\title{
Air Quality Index, Indicatory Air Pollutants and Impact of COVID-19 Event on the Air Quality near Central China
}

\author{
Kaijie Xu' ${ }^{1}$, Kangping Cui ${ }^{1 *}$, Li-Hao Young ${ }^{2}$, Ya-Fen Wang ${ }^{3}$, Yen-Kung Hsieh ${ }^{4 *}$, Shun Wan ${ }^{1}$, \\ Jiajia Zhang ${ }^{1}$
}

${ }^{1}$ School of Resources and Environmental Engineering, Hefei University of Technology, Hefei 230009, China

${ }^{2}$ Department of Occupational Safety and Health, China Medical University, Taichung 40402, Taiwan

${ }^{3}$ Department of Environmental Engineering, Chung-Yuan Christian University, Taoyuan 32023, Taiwan

${ }^{4}$ Marine Ecology and Conservation Research Center, National Academy of Marine Research, Kaohsiung 80661, Taiwan

\begin{abstract}
Both the air quality index (AQI) and indicatory air pollutants of Anqing, Hefei, and Suzhou near central China from 2017 to 2019, and the impact of COVID-19 epidemic prevention and control actions on air quality were investigated. The combined data for the three cities from 2017 to 2019 indicated that the lowest AQI (averaged 78.1) occurred in the summer season, for which the AQI proportions for classes I, II, III, IV, V, and VI were $25.6 \%, 49.9 \%, 21.9 \%, 2.7 \%, 0 \%$, and $0 \%$, respectively. The highest (AQI average of 112.6) was in winter, for which the proportions were 7.4\%, 39.5\%, 33.3\%, 12.5\%, $7.2 \%$, and $0.1 \%$, respectively. $\mathrm{PM}_{2.5}, \mathrm{PM}_{10}$, and $\mathrm{NO}_{2}$ in order were the most important indicatory air pollutants for AQI classes IV, V, and VI, which all prevailed in winter and spring, while $\mathrm{O}_{3}$ was the indicatory air pollutant that occurred most in summer.

The COVID-19 event, which triggered global attention, broke out at the end of 2019. This study also investigated and compared the air quality levels in the three cities from January to March 2017-2019 with those in 2020. The results showed that during February 2020, in the three cities, the average ambient air concentrations of $\mathrm{PM}_{2.5}, \mathrm{PM}_{10}, \mathrm{SO}_{2}, \mathrm{CO}_{2}$ and $\mathrm{NO}_{2}$ were $41.9 \mu \mathrm{g} \mathrm{m}^{-3}, 50.1 \mu \mathrm{g} \mathrm{m}^{-3}, 2.18 \mathrm{ppb}, 0.48 \mathrm{ppm}$, and $8.97 \mathrm{ppb}$, and were $46.5 \%, 48.9 \%, 52.5 \%, 36.2 \%$, and $52.8 \%$, respectively, lower than those in the same month in 2017-2019, respectively. However, the $\mathrm{O}_{3}$ average concentration (80.6 $\mathrm{ppb}$ ) did not show significant fluctuations and even slightly increased by $3.6 \%$. This is because a lower concentration of $\mathrm{NO}_{2}$ resulted in constraints on the reaction of $\mathrm{NO}+\mathrm{O}_{3}$, so the $\mathrm{O}_{3}$ level could not be effectively further reduced. In addition, this study also analyzed and compared the five highest daily AQIs from February 2017-2019 with those of 2020 for the three cities. The mean AQI for the 5 days with the highest daily AQI (averaged 122.6) in February 2020 was $45.1 \%$ lower than that for February 2017-2019 (averaging 223.2), and the indicatory air pollutant was always $\mathrm{PM}_{2.5}$, which decreased by $46.7 \%$ (from 173.6 to $92.6 \mu \mathrm{g} \mathrm{m}^{-3}$ ). It is clear that during the COVID-19 epidemic prevention and control action periods, the air quality near central China improved significantly.
\end{abstract}

Keywords: COVID-19; AQI; $\mathrm{PM}_{2.5} ; \mathrm{PM}_{10} ; \mathrm{SO}_{2} ; \mathrm{CO} ; \mathrm{NO}_{2} ; \mathrm{O}_{3}$.

\section{INTRODUCTION}

With the progress of society and the continuous improvement of the level of industrialization, air pollution is becoming increasingly serious. It poses harm to human health and has become a global environmental problem that is difficult to solve or irreversible (Chatterton et al., 2000).

In January 2013, a continuous haze air quality crisis million people. It is considered to be the worst air pollution occurred

\footnotetext{
* Corresponding author.

E-mail address: cuikangping@163.com (K. Cui); yk886963@naor.oac.gov.tw (Y.K. Hsieh)
}

across a large area of China, affecting more than 8 event in China since the $20^{\text {th }}$ century (Wang et al., 2014). In recent years, large amounts of polluted air stream and frequent environmental pollution problems have affected human health and reduced average human life expectancy. Therefore, environmental awareness and the demand for a healthy environment are also increasing. A World Health Organization (WHO) report states that in 2012, seven million deaths were caused by air pollution worldwide (WHO, 2014). Studies have shown that fine particulate pollution $\left(\mathrm{PM}_{2.5}\right)$ is highly correlated with population mortality and morbidity (Shen $e t$ $a l ., 2017)$. Sulfur dioxide in the atmosphere can affect the respiratory system and lung function and can stimulate the respiratory tract, thereby aggravating asthma and chronic bronchitis in humans, and making people more vulnerable 
to diseases such as respiratory infections. $\mathrm{O}_{3}$ pollution, which has become increasingly prominent in recent years, can also cause respiratory diseases and increase the possibility of lung infections. Therefore, the risk of death in patients with heart and lung diseases is also greater (Turner et al., 2016). In recent years, various diseases caused by air pollution have been on the rise. It is estimated that 2.5 million deaths are caused by indoor and outdoor air pollution each year (Kulmala, 2015).

At the end of 2019, a novel pneumonia broke out, which the World Health Organization named "COVID-19" (Corona Virus Disease-19). The COVID-19 pathogen was found to be a novel coronavirus similar to SARS-CoV-2. The COVID-19 is a new type of acute respiratory infectious disease, which has characteristics that include rapid transmission, a wide range, and strong infectivity. According to data released by the World Health Organization, as of May 6,2020 , the cumulative number of confirmed cases of COVID-19 in the world reached 3,525,116 cases and there were 243,540 deaths (Data were obtained from the platform: http://news.cctv.com/). In order to prevent the spread of the epidemic on a large scale, on January 23, 2020, the Chinese government imposed a travel ban on Wuhan and other provinces, which significantly restricted population movement. Since then, all of the provinces and cities have successively initiated first-level responses to major public health emergencies, and human activities such as industrial production and transportation have sharply decreased. According to previous studies, in central China, winter is the season when air pollution is most serious, and $\mathrm{PM}_{2.5}$ pollution is particularly prevalent (Wang et al., 2018). This is because the temperature is relatively low, and the vertical convection in the atmosphere is weak, which leads to a temperature inversion that is not conducive to the dispersion of pollutants. On the other hand, a large number of coal-fired emissions are caused by residential heating and industries
(Lee et al., 2018; Zhao et al., 2018). However, February 2020 was different. Due to the impact of the COVID-19 event, industrial, construction, and transportation activities in China almost stopped. These prevention and control actions for COVID-19 were closely related to variations in air quality. Therefore, in this study, the air quality levels of three cities (Anqing, Hefei, and Suzhou) in Anhui Province were investigated, compared, and discussed for the nonepidemic period and the epidemic prevention and control period in order to gain more insight into the variations in air quality during that period.

The Air Quality Index (AQI) is used by government agencies to communicate to the public how polluted the air currently is and provides short-term or long-term effects of air pollution on public health. The establishment of ambient air quality standards can provide a basis for and guarantee the management of ambient air quality in order to protect human health, maintain ecological environmental safety, and promote harmonious, sustainable development that protects people, society, and nature (Fang et al., 2009).

\section{METHODS}

The air quality in three cities in Anhui Province (near central China) was analyzed: Anqing $\left(31^{\circ} 52^{\prime} \mathrm{N}, 117.17 \mathrm{E}\right)$, Hefei $\left(31^{\circ} 52^{\prime} \mathrm{N}, 117^{\circ} 17^{\prime} \mathrm{E}\right)$, and Suzhou $\left(33^{\circ} 38^{\prime} \mathrm{N}, 116.58 \mathrm{E}\right)$ (Fig. 1), from January to March, 2017-2020.

Anqing City is located in the southwestern part of Anhui Province and on the north bank of the lower reaches of the Yangtze river. There is a subtropical wet monsoon climate along the river. Hefei City is located in the central part of Anhui Province with a subtropical humid monsoon climate. Suzhou City is located in the northernmost part of Anhui with a warm temperate and semi-humid monsoon climate. In recent years, the economy of central China has developed rapidly, people's living standards have improved, and at the

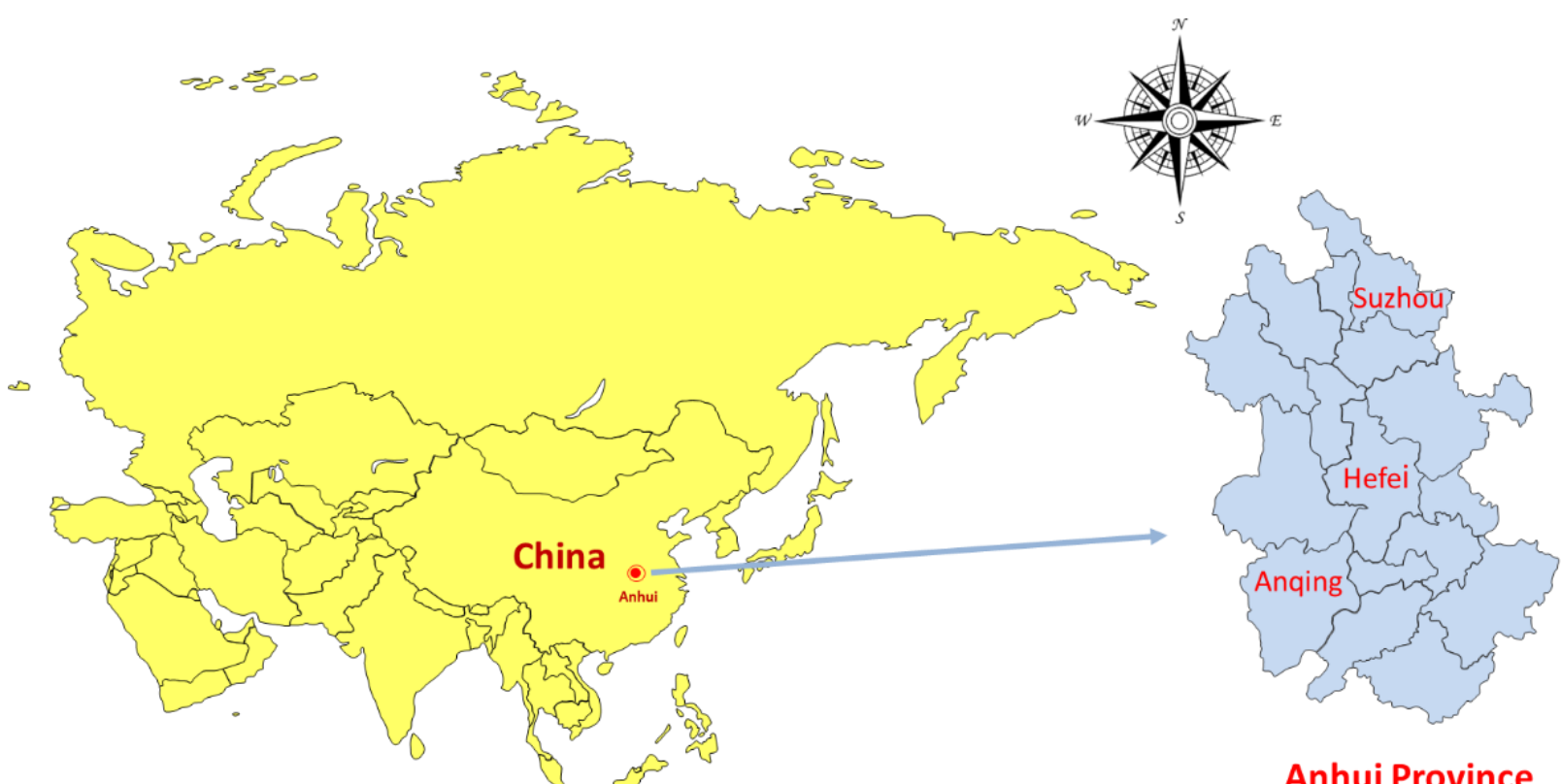

Fig. 1. Location of Anqing, Hefei, Suzhou in Anhui Province, near central China. 
same time, the public's requirements for environmental quality have also increased. This study has important reference significance for human health and urban environmental protection. Data were obtained from the platform: http://www.aqistudy.cn/.

\section{Air Quality Index (AQI)}

The AQI is a dimensionless index that quantitatively describes the status of air quality. As indicated in Eq. (1), the sub-AQI of the six criteria pollutants $\left(\mathrm{PM}_{2.5}, \mathrm{PM}_{10}, \mathrm{SO}_{2}\right.$, $\mathrm{CO}, \mathrm{NO}_{2}$, and $\mathrm{O}_{3}$ ) were first calculated with the observation concentrations. The AQI comes from the maximum of the sub-AQI of all pollutants, as shown in Eq. (2), where when the AQI is higher than 50, the contributor of the maximum sub-AQI is defined as the primary pollutant on that day (She et al., 2017; Shen et al., 2017).

$$
I A Q I_{P}=\frac{I_{\text {high }}-I_{\text {low }}}{C_{\text {high }}-C_{\text {low }}}\left(C_{P}-C_{\text {low }}\right)+I_{\text {low }}
$$

$A Q I=\max \left(I_{1}, I_{2}, \ldots, I_{n}\right)$

$I A Q I_{P}$ : the air quality sub index for air pollutant $\mathrm{p}$. $C_{P}$ : the concentration of pollutant $\mathrm{p}$.

$C_{\text {low }}$ : the concentration breakpoint that is $\leq C_{P}$.

$C_{\text {high }}$ : the concentration breakpoint that is $\geq C_{P}$.

$I_{\text {low }}$ : the index breakpoint corresponding to $C_{\text {low }}$.

$I_{\text {high }}$ : the index breakpoint corresponding to $C_{h i g h}$.

Air quality is closely related to human health. The daily AQIs are calculated based on the 24-hour average concentrations of $\mathrm{PM}_{2.5}, \mathrm{PM}_{10}, \mathrm{SO}_{2}, \mathrm{CO}, \mathrm{NO}_{2}$, and the daily average 8-hour maximum concentration of $\mathrm{O}_{3}$. According to the United States Environmental Protection Agency (US EPA) AQI, the ranges of AQI values related to air quality can be classified into six classes (Zhao et al., 2018):

Class I: 0-50, Good, Green.

Class II: 51-100, Moderate, Yellow.

Class III: 101-150, Unhealthy for sensitive Groups, Orange.

Class IV: 151-200, Unhealthy, Red.

Class V: 201-300, Very unhealthy, Purple.

Class VI: 300-500, Hazardous, Maroon.

\section{RESULTS AND DISCUSSION}

\section{AQI Distribution}

The Air Quality Index (AQI) is used to assess the state of air quality and its impact on human health, thereby providing guidance.

The proportions of the six AQI classes in different seasons for Anqing, Hefei and Suzhou in 2017-2019 are shown in Figs. 2(a)-2(d).

The combined data for the three years in Anqing from 2017-2019, in spring, summer, fall, and winter (Fig. 2(a)) show that the daily AQI ranged between 22 and 157, 20 and 170, 20 and 182, and 22 and 303, and averaged 76.3, 64.6, 75.5 , and 108.5 , respectively. In the meanwhile, in spring, the proportions of AQI classes I, II, III, IV, V, and VI were $13.5 \%, 74.5 \%, 11.7 \%, 0.4 \%, 0 \%$, and $0 \%$, respectively. In summer, the proportions of classes I, II, III, IV, V, and VI were $39.5 \%, 48.2 \%, 11.6 \%, 0.7 \%, 0 \%$, and $0 \%$, respectively. In fall, the proportions were $22.7 \%, 58.2 \%, 17.6 \%, 1.5 \%, 0 \%$, and $0 \%$, respectively, and in winter, they were $10.7 \%, 41.5 \%$, $28.9 \%, 10.4 \%, 8.1 \%$, and $0.4 \%$, respectively. According to the data under investigation from 2017-2019, the most common indicatory air pollutants in Anqing in spring, summer, fall, and winter were $\mathrm{PM}_{2.5}, \mathrm{O}_{3}, \mathrm{O}_{3}$, and $\mathrm{PM}_{2.5}$, respectively. It can be seen that the air quality in summer was obviously better than that in winter.

The combined data for the three years in Hefei from 20172019 in spring, summer, fall, and winter (Fig. 2(b)) show that the daily AQI ranged between 32 and 188, 14 and 200, 29 and 222, and 28 and 285, and averaged 83.7, 79.8, 78.3, and 106.3 , respectively. In the meanwhile, in spring, the proportions of AQI classes I, II, III, IV, V, and VI were $10.0 \%$, $67.4 \%, 21.1 \%, 1.5 \%, 0 \%$, and $0 \%$, respectively. In summer, the proportions of classes I, II, III, IV, V, and VI were $21.0 \%, 52.9 \%, 23.9 \%, 2.2 \%, 0 \%$, and $0 \%$, respectively. In fall, the proportions were $18.1 \%, 60.9 \%, 17.7 \%, 3.0 \%$, $0.4 \%$, and $0 \%$, respectively, and in winter, they were $8.5 \%$, $41.1 \%, 35.9 \%, 10.4 \%, 4.1 \%$, and $0 \%$, respectively. According to the data under investigation from 2017-2019, the most common indicatory air pollutants in Hefei in spring, summer, fall, and winter were $\mathrm{PM}_{2.5}, \mathrm{O}_{3}, \mathrm{NO}_{2}$, and $\mathrm{PM}_{2.5}$, and it can be seen that the air quality in Hefei was slightly worse than that in Anqing. The data shows that Hefei's vehicle ownership (2.0 million, 2018) is much higher than that of Anqing (0.9 million, 2018) (http://www.yearbookchina.com/), and motor vehicle exhaust is an important contributor of ambient $\mathrm{NO}_{2}$ and $\mathrm{PM}_{2.5}$, which may be the reason for the poor air quality in Hefei in summer and fall.

The combined data for the three years in Suzhou from 2017-2019 in spring, summer, fall, and winter (Fig. 2(c)) show that the daily AQI ranged between 35 and 500, 21 and 187, 33 and 431, and 39 and 300, and averaged 93.4, 89.8, 89.8, and 123.1, respectively. In the meanwhile, in spring, the proportions of AQI classes I, II, III, IV, V, and VI were $4.4 \%, 63.3 \%, 26.3 \%, 5.2 \%, 0.4 \%$, and $0.4 \%$, respectively. In summer, the proportions of classes I, II, III, IV, V, and VI were $16.3 \%, 48.6 \%, 30.1 \%, 5.1 \%, 0 \%$, and $0 \%$, respectively. In fall, the proportions were $9.6 \%, 58.1 \%, 27.4 \%, 3.7 \%$, $0.7 \%$, and $0.4 \%$, respectively, and in winter, they were $3.0 \%, 35.9 \%, 35.2 \%, 16.7 \%, 9.3 \%$, and $0 \%$, respectively. According to the data under investigation from 2017-2019, the most common indicatory air pollutants in Suzhou in spring, summer, fall, and winter were $\mathrm{O}_{3}, \mathrm{O}_{3}, \mathrm{NO}_{2}$, and $\mathrm{PM}_{2.5}$, and compared with Anqing and Hefei, the air quality in Suzhou was the worst. From 2017-2019, the proportion of AQI class VI in fall was $0.4 \%$, which indicated that serious air pollution incidents occurred. Suzhou is the northernmost of the three cities. Due to the monsoon, there may be many pollutants from northern cities in the atmosphere in Suzhou, including the precursors that form $\mathrm{O}_{3}$. Weather conditions that are not conducive to the spread of pollutants and the large amount of coal-fired emissions caused by residents' heating are important causes of severe air pollution in winter.

Fig. 2(d) shows the proportions of the six AQI classes for the three cities in spring, summer, fall, and winter from 


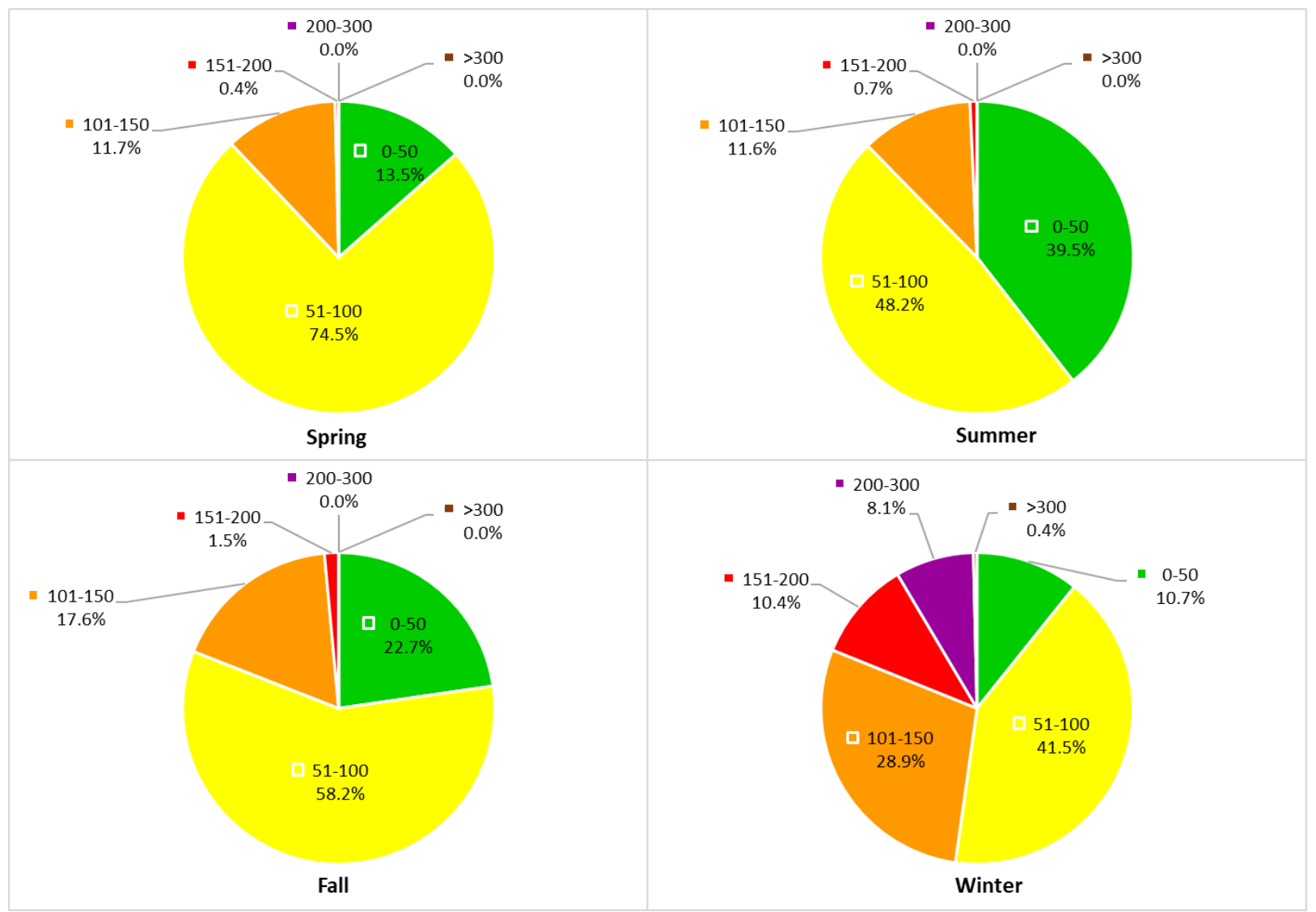

Fig. 2(a). The proportions of the six AQI classes for Anqing in spring, summer, fall, and winter in 2017-2019.

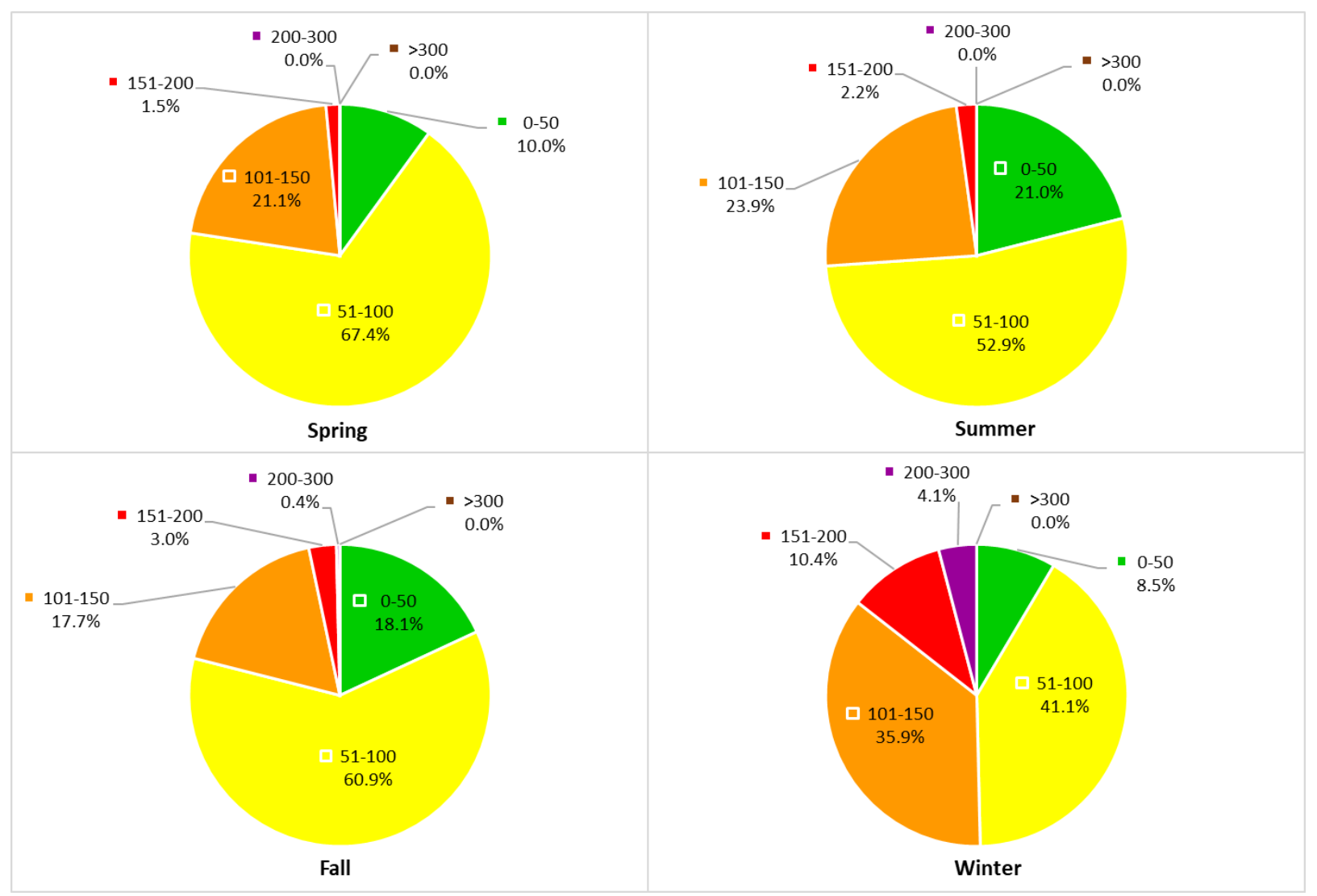

Fig. 2(b). The proportions of the six AQI classes for Hefei in spring, summer, fall, and winter in 2017-2019. 


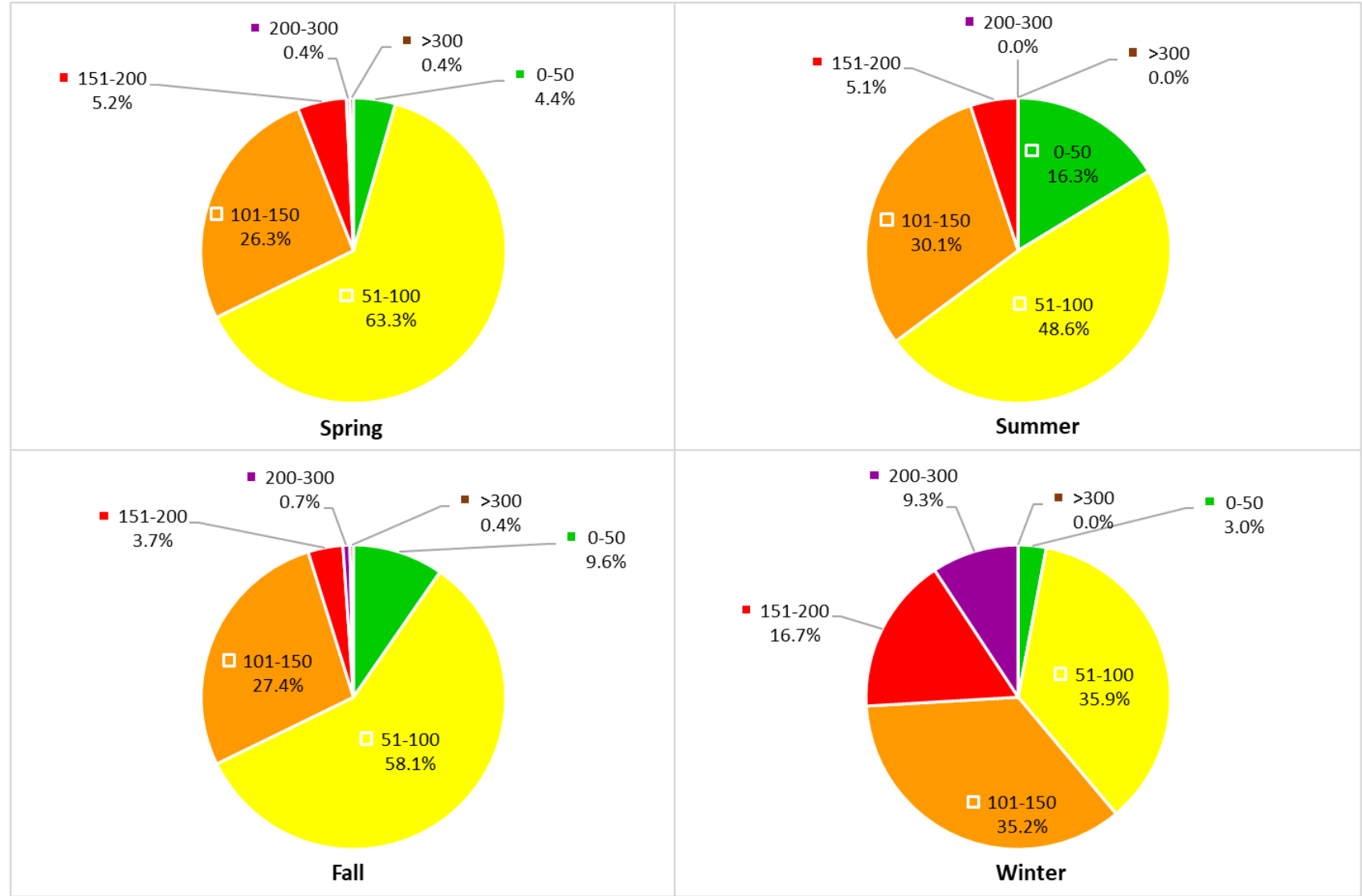

Fig. 2(c). The proportions of the six AQI classes for Suzhou in spring, summer, fall, and winter in 2017-2019.

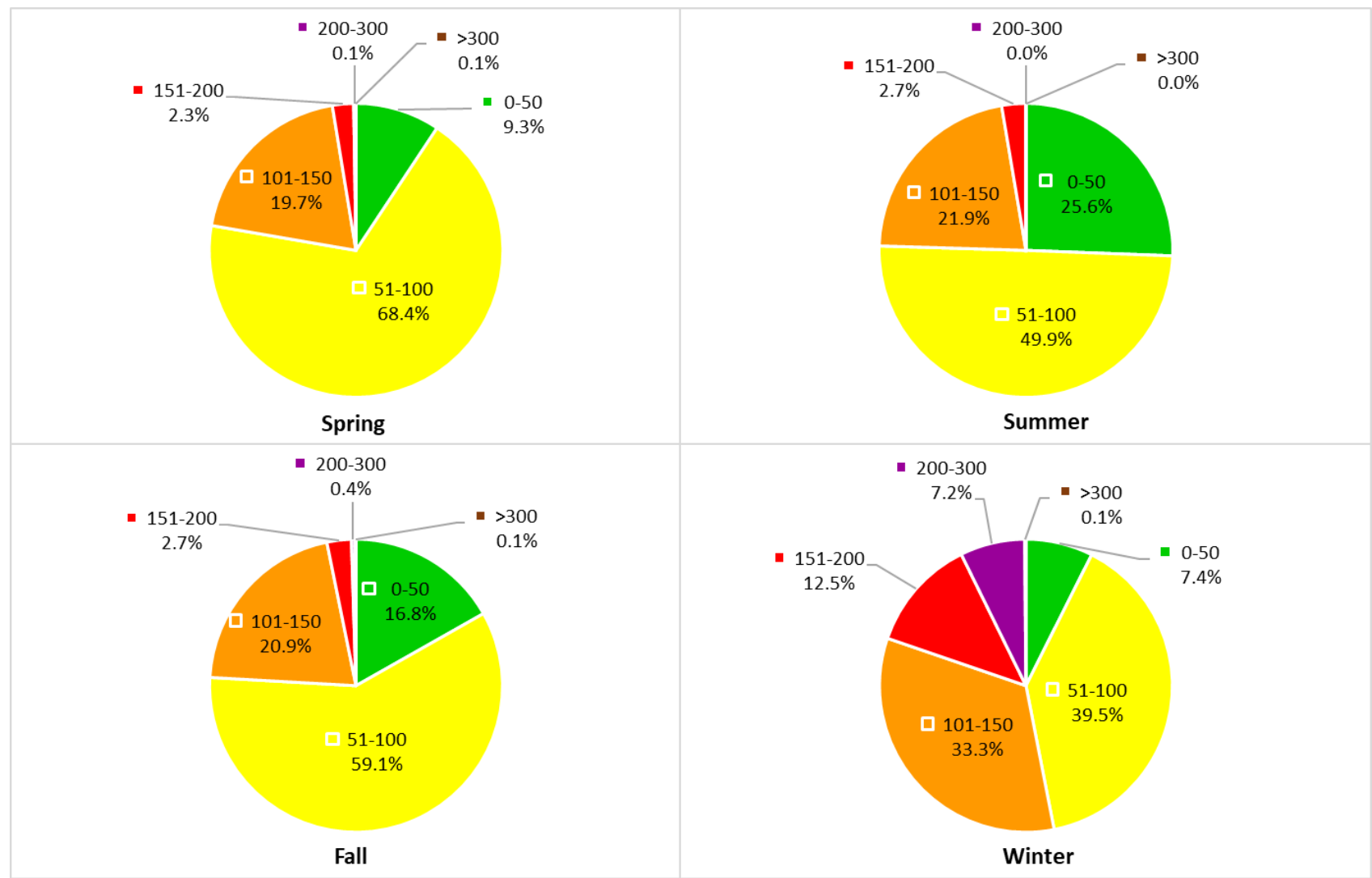

Fig. 2(d). The proportions of the six AQI classes for the three-city in spring, summer, fall, and winter in 2017-2019. 
2017-2019. In spring, the proportions of AQI classes I, II, III, IV, V, and VI for the three cities were $9.3 \%, 68.4 \%$, $19.7 \%, 2.3 \%, 0.1 \%$, and $0.1 \%$, respectively. In summer, the proportions of classes I, II, III, IV, V, and VI were $25.6 \%$, $49.9 \%, 21.9 \%, 2.7 \%, 0 \%$, and $0 \%$, respectively. In fall, the proportions were $16.8 \%, 59.1 \%, 20.9 \%, 2.7 \%, 0.4 \%$, and $0.1 \%$, respectively, and in winter, they were $7.4 \%, 39.5 \%$, $33.3 \%, 12.5 \%, 7.2 \%$, and $0.1 \%$, respectively. In general, the AQI levels of the three cities in the different seasons were in order as follows: winter $>$ spring $>$ fall $>$ summer, which was consistent with the results of Shen et al. (2017) indicating that the air quality in summer was much better than that in winter. In summer, higher temperature and air humidity are conducive to the dilution and diffusion of pollutants, and the concentration of particulate matter in the air is much lower than in winter. In winter, a large amount of coal is used for heating, and the exhaust gas produced by combustion greatly contributes to the accumulation of atmospheric particulate matter. Due to the low temperature in winter, the vertical exchange of the atmosphere is weak, and the inverse temperature phenomenon is significant, which is not conducive to the dilution and diffusion of pollutants in the air, so the air quality in winter is poor.

In terms of annual AQI characteristics, in Anqing, in 2017, 2018, and 2019, the daily AQI ranged from 21 to 285 , 20 to 265 , and 20 to 303 , respectively, and averaged 83.1 , 77.3, and 83.2, respectively. In Hefei, in 2017, 2018, and 2019, the daily AQI ranged from 29 to 285,24 to 231, and 14 to 216 , respectively, and averaged $95.1,79.5$, and 87.6, respectively. As for Suzhou, in 2017, 2018, and 2019, the daily AQI ranged from 32 to 500, 24 to 251, and 21 to 431, respectively, and averaged 109.4, 91.2, and 97.5, respectively. Based on the analysis of the observation data for the three years, the AQI level rankings of the three cities were as follows: Suzhou > Hefei > Anqing, which showed that among the three cities from 2017-2019, Anqing had the best air quality, and Suzhou had the worst.

It can be seen that during the three-year observation period, the air quality in Anqing did not improve significantly, but the air quality in Hefei and Suzhou improved to some extent. Data from the three-year observation period show that the average annual AQI of the three cities reached the lowest in 2018, but the air quality in 2019 showed a certain degree of deterioration. The AQI of Suzhou was higher than that in Anqing and Hefei, which indicates more serious air pollution. In addition, in 2017 and 2019, the maximum AQI in Suzhou reached 500 and 431, respectively, indicating that serious air pollution incidents occurred in Suzhou during this period.

\section{Indicatory Air Pollutants}

In this study, the indicatory air pollutants of AQI classes IV, V, and VI in the three cities during the period 2017-2019 were also analyzed.

As shown in Table 1(a), during the three-year period under observation (2017-2019), in Anqing, the daily AQI comprised classes IV, V, and VI for a total of 58 days. There were 35 days for Class IV, where the AQI ranged from 152199 and averaged 173.6. The main indicatory air pollutant was $\mathrm{PM}_{2.5}$ (30 days), for which the concentration ranged from $89-163 \mu \mathrm{g} \mathrm{m}^{-3}$ and averaged $132.5 \mu \mathrm{g} \mathrm{m}^{-3}$, and followed by $\mathrm{O}_{3}$ ( 5 days), which ranged from $102-110 \mathrm{ppb}$ and averaged $105.2 \mathrm{ppb}$. There were 22 days for Class V, where the AQI ranged from 201-285 and averaged 222.4. The indicatory air pollutant for those days was $\mathrm{PM}_{2.5}$, ranging from 147$235 \mu \mathrm{g} \mathrm{m}^{-3}$ and averaging $170.9 \mu \mathrm{g} \mathrm{m}^{-3}$. There was 1 day that was Class VI, where the AQI was 303, and the indicatory air pollutant was $\mathrm{PM}_{2.5}\left(253 \mu \mathrm{g} \mathrm{m}^{-3}\right)$.

As shown in Table 1(b), during the three-year period, in Hefei, there were 58 days when the daily AQI fell into classes IV, V, and VI. There were 46 days for Class IV when the AQI ranged from 151-200 and averaged 172.3. The main indicatory air pollutant was $\mathrm{PM}_{2.5}$ (33 days), followed by $\mathrm{O}_{3}$ (10 days), $\mathrm{PM}_{10}$ (2 days), and $\mathrm{NO}_{2}$ (1 day), for which the concentration for each air pollutant ranged from 111$222 \mu \mathrm{g} \mathrm{m}^{-3}, 101-126 \mathrm{ppb}, 253-308 \mu_{\mathrm{g} \mathrm{m}}^{-3}$, and $28.7 \mathrm{ppb}$ and averaged $132.5 \mu \mathrm{g} \mathrm{m}^{-3}, 109.5 \mathrm{ppb}, 280.5 \mu \mathrm{g} \mathrm{m}^{-3}$, and $28.7 \mathrm{ppb}$, respectively. There were 12 days that were Class $\mathrm{V}$, where the AQI ranged from 202-285 and averaged 225.6. The indicatory air pollutant for those days was $\mathrm{PM}_{2.5}$, ranging 76-235 $\mu \mathrm{g} \mathrm{m}^{-3}$ and averaging $167.4 \mu \mathrm{g} \mathrm{m}^{-3}$. There were no Class VI days in the three year period in Hefei.

As shown in Table 1(c), during the three years, in Suzhou, there were 113 days when the daily AQI comprised classes IV, V, and VI. There were 83 days for Class IV, where the AQI ranged from 151-195 and averaged 169.8. The main indicatory air pollutant was $\mathrm{PM}_{2.5}$ (59 days), followed by $\mathrm{O}_{3}$ (22 days), and $\mathrm{PM}_{10}$ (2 days), and the concentrations of each air pollutant ranged from 116-146 $\mu \mathrm{g} \mathrm{m}^{-3}, 101-120 \mathrm{ppb}$, and $254-287 \mu \mathrm{g} \mathrm{m}^{-3}$ and averaged $131.2 \mu \mathrm{g} \mathrm{m}^{-3}, 106.2 \mathrm{ppb}$, and $270.5 \mu \mathrm{g} \mathrm{m}^{-3}$, respectively. There were 28 days that fell into Class V, and the AQI ranged from 201-300 and averaged 232.3. The indicatory air pollutant for those days was $\mathrm{PM}_{2.5}$, ranging from $119-250 \mu \mathrm{g} \mathrm{m}^{-3}$ and averaging $176.5 \mu \mathrm{g} \mathrm{m}^{-3}$. For Class VI, there were 2 days, with the AQI ranging from 431-500 and averaging 465.5, and the indicatory air pollutant was $\mathrm{PM}_{10}\left(531 \mu \mathrm{g} \mathrm{m}^{-3}\right)$, which shows that serious air pollution incidents occurred.

The combined three-year data for the three cities indicated that in classes IV, V, and VI, $\mathrm{PM}_{2.5}$ was the most important indicatory air pollutant, followed by $\mathrm{O}_{3}, \mathrm{PM}_{10}$, and $\mathrm{NO}_{2}$. The vast majority of AQI classes IV, V, and VI occurred in winter and spring, with the exception of the days when the indicatory air pollutant was $\mathrm{O}_{3}$, which occurred most in summer. This is because the higher temperature and stronger solar radiation in summer are more conducive to the production and accumulation of $\mathrm{O}_{3}$.

\section{The Impact of the COVID-19 Event on Air Quality Comparison of Air Pollutants}

The average concentrations for $\mathrm{PM}_{2.5}, \mathrm{PM}_{10}, \mathrm{SO}_{2}, \mathrm{CO}$, $\mathrm{NO}_{2}$, and $\mathrm{O}_{3}$ in January, February, and March 2017-2019 and those for 2020, are shown and compared in Fig. 3(A)$3(\mathrm{~F})$, respectively.

\section{$\underline{\mathrm{PM}_{2.5}}$ Concentration}

$\mathrm{PM}_{2.5}$ mainly comes from thermal power generation, industrial production, automobile exhaust, the burning of 
Table 1(a). Indicatory air pollutants of AQI classes IV, V, and VI in Anqing from 2017-2019 (Units for different air pollutants, $\left.\mathrm{PM}_{2.5}\left(\mu \mathrm{g} \mathrm{m}^{-3}\right), \mathrm{O}_{3}(\mathrm{ppb})\right)$.

\begin{tabular}{lllllll}
\hline \multirow{2}{*}{ AQI Class } & \multicolumn{3}{c}{ AQI } & & \multicolumn{3}{c}{ Indicatory Air Pollutants } \\
\cline { 2 - 3 } \cline { 5 - 6 } & Range & Mean & & & Range & Mean \\
\hline VI (1 day) & 303 & 303 & & $\mathrm{PM}_{2.5}$ & 253 & 253 \\
V (22 days) & $201-285$ & 222.4 & & $\mathrm{PM}_{2.5}$ & $147-235$ & 170.9 \\
IV (35 days) & $152-199$ & 173.6 & & $\mathrm{PM}_{2.5}$ (30 days) & $89-163$ & 132.5 \\
& & & $\mathrm{O}_{3}$ (5 days) & $102-110$ & 105.2 \\
\hline
\end{tabular}

Table 1(b). Indicatory air pollutants of AQI classes IV, V, and VI in Hefei from 2017-2019 (Units for different air pollutants, $\left.\mathrm{PM}_{2.5}\left(\mu \mathrm{g} \mathrm{m}^{-3}\right), \mathrm{PM}_{10}\left(\mu \mathrm{g} \mathrm{m}^{-3}\right), \mathrm{NO}_{2}(\mathrm{ppb}), \mathrm{O}_{3}(\mathrm{ppb})\right)$.

\begin{tabular}{|c|c|c|c|c|c|}
\hline \multirow{2}{*}{ AQI Class } & \multicolumn{2}{|c|}{ AQI } & \multicolumn{3}{|c|}{ Indicatory Air Pollutants } \\
\hline & Range & Mean & & Range & Mean \\
\hline VI (0 day) & 1 & 1 & 1 & 1 & 1 \\
\hline V (12 days) & $202-285$ & 225.6 & $\mathrm{PM}_{2.5}$ & $76-235$ & 167.4 \\
\hline \multirow{4}{*}{ IV (46 days) } & $151-200$ & 172.3 & $\mathrm{PM}_{2.5}$ (33 days) & $111-222$ & 132.5 \\
\hline & & & $\mathrm{O}_{3}(10$ days $)$ & $101-126$ & 109.5 \\
\hline & & & $\mathrm{PM}_{10}$ (2 days) & $253-308$ & 280.5 \\
\hline & & & $\mathrm{NO}_{2}$ (1 day) & 28.7 & 28.7 \\
\hline
\end{tabular}

Table 1(c). Indicatory air pollutants of AQI classes IV, V, and VI in Suzhou from 2017-2019 (Units for different air pollutants, $\left.\mathrm{PM}_{2.5}\left(\mu \mathrm{g} \mathrm{m}^{-3}\right), \mathrm{PM}_{10}\left(\mu \mathrm{g} \mathrm{m}^{-3}\right), \mathrm{O}_{3}(\mathrm{ppb})\right)$.

\begin{tabular}{lllllll}
\hline \multirow{2}{*}{ AQI Class } & \multicolumn{3}{c}{ AQI } & & \multicolumn{3}{c}{ Indicatory Air Pollutants } \\
\cline { 2 - 3 } \cline { 5 - 6 } & Range & Mean & & Range & Mean \\
\hline VI (2 days) & $431-500$ & 465.5 & & $\mathrm{PM}_{10}$ & 531 & 531 \\
V (28 days) & $201-300$ & 232.3 & & $\mathrm{PM}_{2.5}$ & $119-250$ & 176.5 \\
IV (83 days) & $151-195$ & 169.8 & & $\mathrm{PM}_{2.5}$ (59 days) & $116-146$ & 131.2 \\
& & & & $\mathrm{O}_{3}$ (22 days) & $101-120$ & 106.2 \\
& & & $\mathrm{PM}_{10}$ (2 days) & $254-287$ & 270.5 \\
\hline
\end{tabular}

biomass, secondary generation, road dust, and other processes. $\mathrm{PM}_{2.5}$ is composed of primary particles directly discharged into the air and secondary particles generated by photochemical reactions of gaseous pollutants in the air. $\mathrm{PM}_{2.5}$ usually accumulates in the human respiratory tract and causes very serious harm to human health (Tao et al., 2009; Xu et al., 2017; Wu et al., 2019b).

As shown in Fig. 3(A)(a), in the month of January 2017 2019, in Anqing, Hefei, and Suzhou, the $\mathrm{PM}_{2.5}$ concentrations ranged between 9.0 and 235, between 16 and 202, and between 32 and $250 \mu \mathrm{g} \mathrm{m}^{-3}$ and averaged 92.8, 87.5, and $106.5 \mu \mathrm{g} \mathrm{m}^{-3}$, respectively. Concentrations in January 2020 were in the range of 9.0-110, 20-138, and 20-223 $\mathrm{\mu g} \mathrm{m}^{-3}$, and averaged 56.0, 64.6, and $100.7 \mu \mathrm{g} \mathrm{m}^{-3}$, respectively, which was $39.7 \%, 26.2 \%$, and $5.4 \%$ lower than those in January 2017-2019. Based on the data from the three cities, during January 2020, the average $\mathrm{PM}_{2.5}$ decreased by $23.8 \%$ compared with that in January 2017-2019.

As shown in Fig. 3(A)(b), in Anqing, Hefei and Suzhou, during February 2017-2019, the $\mathrm{PM}_{2.5}$ concentrations ranged between 21 and 253, between 17 and 145, and between 31 and $151 \mu \mathrm{g} \mathrm{m}^{-3}$, and averaged 75.2, 71.7, and $87.0 \mu \mathrm{g} \mathrm{m}^{-3}$, respectively. Those during February 2020 ranged from 9.0$89,11-92$, and $16-100 \mu \mathrm{g} \mathrm{m}^{-3}$ and averaged $38.7,36.4$, and $50.8 \mu \mathrm{g} \mathrm{m}^{-3}$, respectively, which was $48.6 \%, 49.2 \%$, and 41.6\% lower than those in February 2017-2019. Based on the data from the three cities, during February 2020, the average $\mathrm{PM}_{2.5}$ decreased by $46.5 \%$ compared with that in February 2017-2019.

As shown in Fig. 3(A)(c), in Anqing, Hefei and Suzhou, during March 2017-2019, the $\mathrm{PM}_{2.5}$ concentrations ranged between 15 and 113 , between 9.0 and 110, and between 25 and $149 \mu \mathrm{g} \mathrm{m}^{-3}$, and averaged 53.0, 54.4, and $68.7 \mu \mathrm{g} \mathrm{m}^{-3}$, respectively. Concentrations in March 2020 ranged from 8.0-63, 11-59, and 20-78 $\mu \mathrm{g} \mathrm{m}^{-3}$ and averaged $37.3,34.9$, and $45.6 \mu \mathrm{g} \mathrm{m}^{-3}$, respectively, which was $29.7 \%, 35.8 \%$ and $33.5 \%$ lower than those in March 2017-2019. Based on the data from the three cities, $\mathrm{PM}_{2.5}$ decreased by $33.0 \%$ on average compared with March 2017-2019.

The main sources of atmospheric particulate matter include fossil fuel combustion, motor vehicle exhaust emissions, industrial production, construction, road dust, biomass combustion, secondary particulate matter generation, etc. (Song et al., 2007; Kim and Hopke, 2008). It can be seen that compared with the same period in the previous three years, from January to March 2020, the $\mathrm{PM}_{2.5}$ concentration decreased significantly. In January 2020, the reason for the drop in $\mathrm{PM}_{2.5}$ concentration may have been the Chinese New Year holiday in late January, which led to the temporary closure of most factories. In February and March 2020, the $\mathrm{PM}_{2.5}$ concentration decreased significantly. This is because comprehensive strict epidemic prevention and control actions 

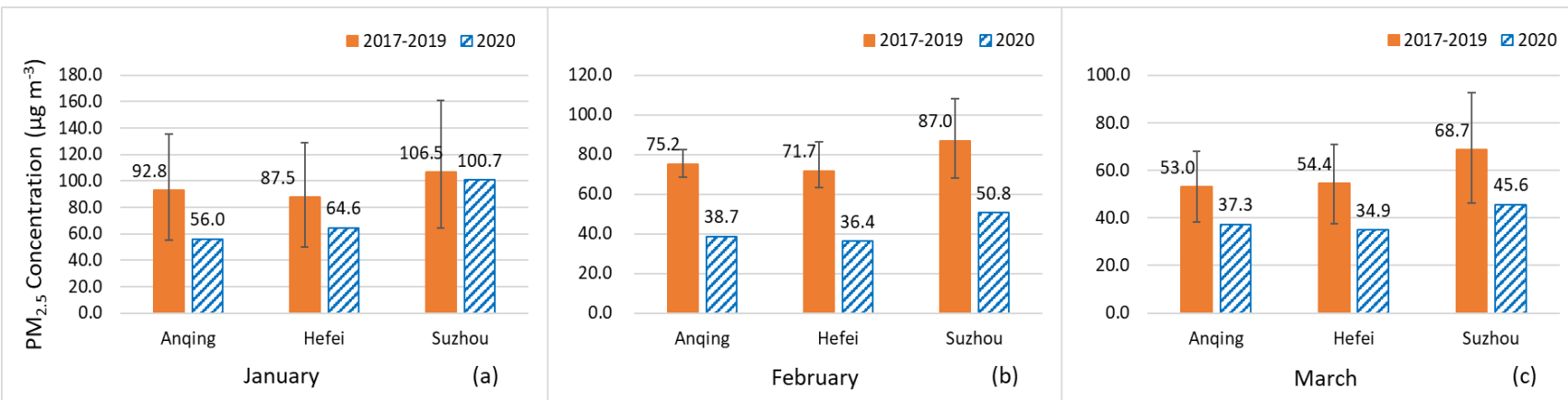

Fig. 3(A). Average $\mathrm{PM}_{2.5}$ concentrations during January, February, and March 2017-2019 and those in 2020, respectively.

were taken in Anhui Province, such as closing factories and restricting traffic. These actions greatly reduced industrial and transportation emissions. In order to prevent the spread of COVID-19, China adopted self-quarantine for residents, which greatly reduced the use of diesel and gasoline vehicles. Therefore, the emissions of fine particulates and PAHs were greatly reduced, which is an important reason for the decrease in atmospheric $\mathrm{PM}_{2.5}$ concentrations (Zhou et al., 2009; Wu et al., 2019a; Wu et al., 2019b).

\section{$\underline{\mathrm{PM}}_{10}$ Concentration}

$\mathrm{PM}_{10}$ refers to solid and liquid particles with an aerodynamic diameters below $10 \mu \mathrm{m}$, which can have a direct negative impact on human health (Matus et al., 2012; Liang et al., 2016). $\mathrm{PM}_{10}$ in the atmosphere comes from natural factors such as sand storms and soil dust, as well as human factors such as coal combustion and building dust (Matawle et al., 2015; Liu et al., 2020).

As shown in Fig. 3(B)(a), in Anqing, Hefei, and Suzhou, from January 2017-2019, the $\mathrm{PM}_{10}$ concentrations ranged between 10 and 258, between 8 and 186, and between 49 and $266 \mu \mathrm{g} \mathrm{m}^{-3}$, and averaged 100.4, 92.2, and $138.1 \mu \mathrm{g} \mathrm{m}^{-3}$, respectively. Concentrations in January 2020 ranged from 11-101, 14-119, and 22-253 $\mathrm{gg} \mathrm{m}^{-3}$ and averaged 53.0, 59.3, and $111.9 \mu \mathrm{g} \mathrm{m}^{-3}$, respectively, which was $47.2 \%$, $35.7 \%$, and 19.0\% lower than those in January 2017-2019. Based on the data from the three cities, during January 2020, the average $\mathrm{PM}_{10}$ decreased by $33.9 \%$ compared with that in January 2017-2019.

As shown in Fig. 3(B)(b), in Anqing, Hefei, and Suzhou, during February 2017-2019, the $\mathrm{PM}_{10}$ concentrations ranged between 15 and 367 , between 15 and 179 , and between 47 and $254 \mu \mathrm{g} \mathrm{m}^{-3}$, and averaged 89.2, 83.3, and $120.4 \mu \mathrm{g} \mathrm{m}^{-3}$, respectively. Concentrations in February 2020 ranged from

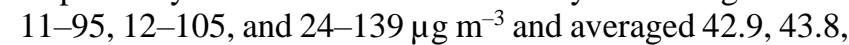
and $63.4 \mu \mathrm{g} \mathrm{m}^{-3}$, respectively, which was $51.9 \%, 47.4 \%$, and $47.3 \%$ lower than those in February 2017-2019. Based on the data from the three cities, in February 2020, the average $\mathrm{PM}_{10}$ decreased by $48.9 \%$ compared with that in February 2017-2019.

As shown in Fig. 3(B)(c), in Anqing, Hefei, and Suzhou, in March 2017-2019, the $\mathrm{PM}_{10}$ concentrations ranged between 17 and 136, between 15 and 182, and between 47 and $197 \mu \mathrm{g} \mathrm{m}^{-3}$, and averaged 70.2, 79.3, and $104.2 \mu \mathrm{g} \mathrm{m}^{-3}$, respectively. Concentrations in March 2020 ranged from
12-134, 22-200, and 39-138 $\mu \mathrm{g} \mathrm{m}^{-3}$ and averaged 52.4, 60.2 , and $76.8 \mu \mathrm{g} \mathrm{m}^{-3}$, respectively, which was $25.4 \%, 24.1 \%$, and $26.3 \%$ lower than those in March 2017-2019. Based on the data from the three cities, in March 2020, the average $\mathrm{PM}_{10}$ decreased by $25.3 \%$ compared with that in March 2017-2019.

$\mathrm{PM}_{10}$ mainly comes from the extensive application of fossil fuels in transportation, industrial production, building dust, and wind dust. During the epidemic control period, the residents chose to quarantine at home, which led to the stagnation of industrial production, transportation, and construction. The above control actions were of great importance to the significant reduction in ambient air $\mathrm{PM}_{10}$.

\section{$\underline{\mathrm{SO}}_{2}$ Concentration}

$\mathrm{SO}_{2}$ is a major air pollutant and has a wide range of distribution, mainly from the combustion of coal and petroleum and the smelting of sulfur-containing ores. $\mathrm{SO}_{2}$ pollution not only causes environmental problems such as acid rain, but also causes allergic reactions in the human body, causing symptoms such as difficulty with breathing and vomiting.

As shown in Fig. 3(C)(a), in Anqing, Hefei, and Suzhou, in the month of January 2017-2019, the $\mathrm{SO}_{2}$ concentrations ranged between 1.75 and 19.3 , between 1.05 and 10.9, and between 2.10 and $24.5 \mathrm{ppb}$, and averaged 5.02, 3.81, and $6.72 \mathrm{ppb}$, respectively. Concentrations in January 2020 ranged from $1.75-4.90,1.40-3.15$, and $1.40-3.85 \mathrm{ppb}$ and averaged $2.59,2.00$, and $2.21 \mathrm{ppb}$, respectively, which was $48.5 \%$, $47.6 \%$, and $67.1 \%$ lower than those during January 20172019. Based on the data from the three cities, during January 2020 , the average $\mathrm{SO}_{2}$ decreased by $54.4 \%$ compared with that in January 2017-2019.

As shown in Fig. 3(C)(b), in Anqing, Hefei, and Suzhou, in the month of February 2017-2019, the $\mathrm{SO}_{2}$ concentrations ranged between 2.10 and 21.1 , between 0.72 and 8.41, and between 1.75 and $18.2 \mathrm{ppb}$, and averaged 5.14, 3.31, and $5.95 \mathrm{ppb}$, respectively. Concentrations in February 2020 ranged from $1.45-7.05,1.41-3.85$, and $1.42-3.15 \mathrm{ppb}$ and averaged $2.56,1.93$, and $2.05 \mathrm{ppb}$, respectively, which was $50.2 \%, 41.7 \%$, and $65.5 \%$ lower than those in February 2017-2019. Based on the data from the three cities, during February 2020, the average $\mathrm{SO}_{2}$ decreased by $52.5 \%$ compared with that in February 2017-2019.

As shown in Fig. 3(C)(c), in Anqing, Hefei, and Suzhou, in the month of March 2017-2019, the $\mathrm{SO}_{2}$ concentrations 


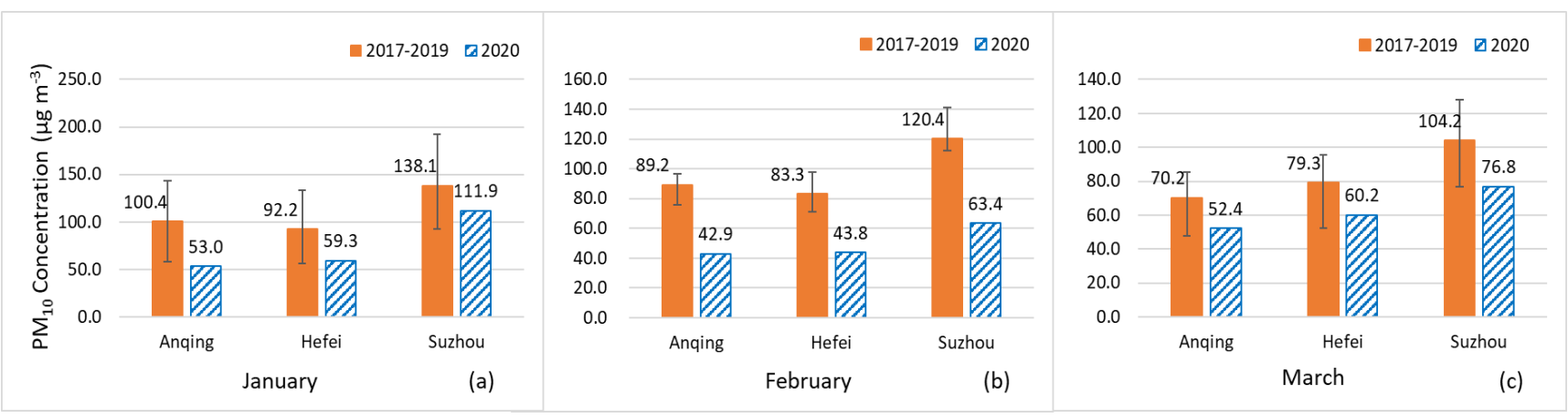

Fig. 3(B). The average concentrations of $\mathrm{PM}_{10}$ in January, February and March 2017-2019 and those in 2020, respectively.

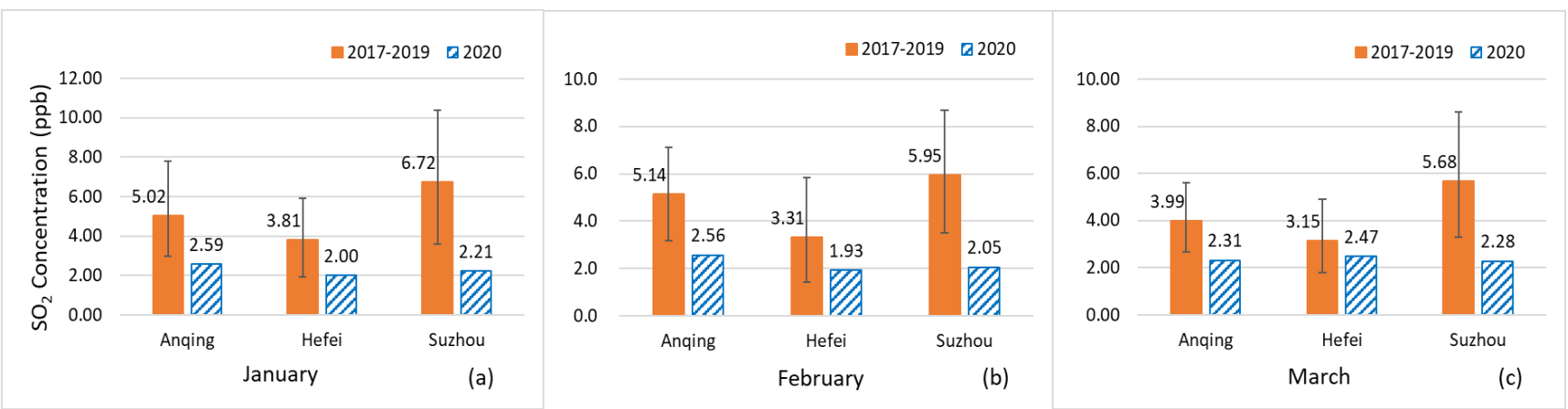

Fig. 3(C). The average concentrations of $\mathrm{SO}_{2}$ in January, February, and March 2017-2019 and those in 2020, respectively.

ranged between 2.11 and 8.42 , between 1.05 and 10.2, and between 1.75 and $13.0 \mathrm{ppb}$, and averaged 3.99, 3.15, and $5.68 \mathrm{ppb}$, respectively. Concentrations in March 2020 ranged from $1.45-3.51,1.40-4.55$, and $1.75-3.85 \mathrm{ppb}$ and averaged $2.31,2.47$, and $2.28 \mathrm{ppb}$, respectively, which was $41.9 \%$, 21.5\%, and 59.8\% lower than those in March 2017-2019. Based on the data from the three cities, during March 2020, the average $\mathrm{SO}_{2}$ decreased by $41.1 \%$ compared with that in March 2017-2019.

The results indicate that from January to March 2020, the level of $\mathrm{SO}_{2}$ decreased significantly compared to the same period in 2017-2019, and were far below the WHO air quality regulatory standards $\left(20 \mu \mathrm{g} \mathrm{m}^{-3}\right.$ or $\left.7.0 \mathrm{ppb}\right)$. Production suspensions due to the Chinese New Year holidays and the restrictions on production activities during the epidemic prevention and control period resulted in a substantial reduction in the burning of fossil fuels, which may be important reasons for the decrease in $\mathrm{SO}_{2}$ concentration.

\section{CO Concentration}

$\mathrm{CO}$ (carbon monoxide) is the third smallest component of carbon in the atmosphere, after $\mathrm{CO}_{2}$ and $\mathrm{CH}_{4}$. The $\mathrm{CO}$ in the atmosphere is mainly from the combustion products resulting when carbonaceous substances are incompletely burned. Factory heating furnaces, power stations, civil boilers, stoves, internal combustion engines, and automobile exhaust gas are the main sources of carbon monoxide.

As shown in Fig. 3(D)(a), in Anqing, Hefei, and Suzhou, in the month of January 2017-2019, the CO concentrations ranged between 0.32 and 1.61 , between 0.41 and 2.24 , and between 0.48 and $3.04 \mathrm{ppm}$, and averaged $0.76,0.92$, and
0.91 ppm, respectively. Concentrations in January 2020 ranged from $0.24-1.04,0.24-1.21$, and $0.41-1.84 \mathrm{ppm}$ and averaged $0.61,0.69$, and $0.86 \mathrm{ppm}$, respectively, which was $19.7 \%, 24.5 \%$, and $5.8 \%$ lower than those in January 20172019. Based on the data from the three cities, in January 2020 , the average CO decreased by $16.7 \%$ compared with that in January 2017-2019.

As shown in Fig. 3(D)(b), in Anqing, Hefei, and Suzhou, in the month of February 2017-2019, the CO concentrations ranged between 0.24 and 1.12 , between 0.32 and 1.21 , and between 0.41 and $1.84 \mathrm{ppm}$, and averaged 0.67, 0.77, and $0.80 \mathrm{ppm}$, respectively. Concentrations in February 2020 ranged from $0.24-0.72,0.32-0.72$, and $0.24-0.88 \mathrm{ppm}$ and averaged $0.46,0.47$, and $0.49 \mathrm{ppm}$, respectively, which was $31.8 \%, 38.6 \%$, and $38.2 \%$ lower than those in February 20172019. Based on the data from the three cities, in February 2020, the average CO decreased by $36.2 \%$ compared with that in February 2017-2019.

As shown in Fig. 3(D)(c), in Anqing, Hefei, and Suzhou, in the month of March 2017-2019, the CO concentrations ranged between 0.32 and 0.96 , between 0.32 and 1.21 , and between 0.24 and $1.23 \mathrm{ppm}$ and averaged $0.59,0.65$, and 0.59 ppm, respectively. Concentrations in March 2020 ranged from $0.32-0.72,0.32-0.81$, and $0.16-0.64 \mathrm{ppm}$ and averaged $0.50,0.49$, and $0.40 \mathrm{ppm}$, respectively, which was $14.8 \%$, $25.8 \%$, and 32.1\% lower than those in March 2017-2019. Based on the data from the three cities, during March 2020, the average CO decreased by $24.2 \%$ compared with that in March 2017-2019.

Similar to the $\mathrm{SO}_{2}$ pattern, in January to March 2020, the $\mathrm{CO}$ concentration also showed a significant decrease 

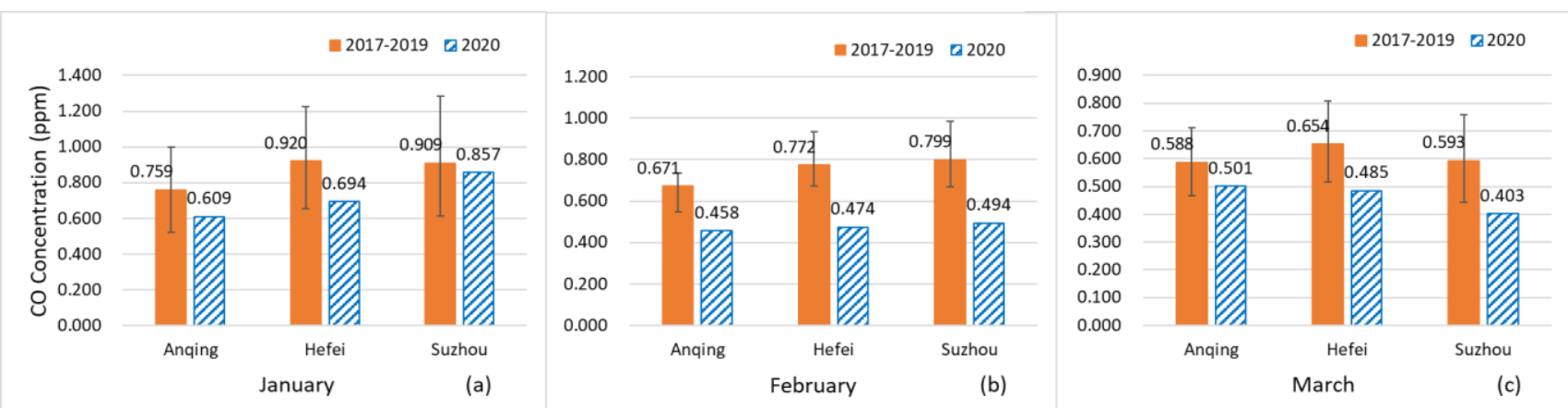

Fig. 3(D). The average concentrations of CO in January, February, and March 2017-2019 and those in 2020, respectively.

compared with the average in the same period in 20172019. This shows that during the Lunar New Year holidays and the epidemic control period, fossil fuel burning activities were reduced, thereby greatly reducing the $\mathrm{CO}$ emissions.

\section{$\mathrm{NO}_{2}$ Concentration}

The main sources of $\mathrm{NO}_{2}$ are the combustion of fossil fuels and the emission of automobile exhaust (Cheng et al., 2018). Compared with the non-epidemic stage, the change in $\mathrm{NO}_{2}$ concentrations was also very obvious.

As shown in Fig. 3(E)(a), in Anqing, Hefei, and Suzhou, in the month of January 2017-2019, the $\mathrm{NO}_{2}$ concentrations ranged between 6.82 and 49.7, between 7.79 and 59.9, and between 7.30 and $47.7 \mathrm{ppb}$, and averaged 21.2, 26.4, and $23.9 \mathrm{ppb}$, respectively. Concentrations in January 2020 ranged from 4.87-25.3, 6.82-36.0, and 5.36-30.2 ppb and averaged 13.5, 20.7, and $15.2 \mathrm{ppb}$, respectively, which was $36.5 \%, 21.7 \%$, and $36.5 \%$ lower than those in January 2017-2019. Based on the data from the three cities, in January 2020, the average $\mathrm{NO}_{2}$ decreased by $31.5 \%$ compared with that in January 2017-2019.

As shown in Fig. 3(E)(b), in Anqing, Hefei, and Suzhou, during February 2017-2019, the $\mathrm{NO}_{2}$ concentrations ranged between 5.36 and 36.0, between 5.84 and 53.1, and between 4.87 and $40.4 \mathrm{ppb}$ and averaged 15.9, 22.6, and $18.9 \mathrm{ppb}$, respectively. Concentrations in the epidemic prevention and control action period (February 2020) ranged from 3.9017.5, 4.87-16.6, and 2.92-17.5 ppb and averaged 8.91, 11.3, and $6.75 \mathrm{ppb}$, respectively, which was $43.8 \%, 50.2 \%$, and 64.4\% lower than those in February 2017-2019. Based on the data from the three cities, in February 2020, the average $\mathrm{NO}_{2}$ decreased by $52.8 \%$ compared with that in February 2017-2019.

As shown in Fig. 3(E)(c), in Anqing, Hefei, and Suzhou, in March 2017-2019, the $\mathrm{NO}_{2}$ concentrations ranged between 6.82 and 38.0, between 9.74 and 66.7, and between 5.84 and $35.1 \mathrm{ppb}$, and averaged $17.8,24.9$, and $19.0 \mathrm{ppb}$, respectively. Concentrations in March 2020 ranged from 5.36-25.3, 8.77-29.7, and 6.82-21.4 ppb and averaged 13.4, 18.1 , and $13.4 \mathrm{ppb}$, respectively, which was $24.8 \%, 27.0 \%$, and 29.6\% lower than those in March 2017-2019. Based on the data from the three cities, during March 2020, the average $\mathrm{NO}_{2}$ decreased by $27.2 \%$ compared with that in March 2017-2019.

Compared with that in the period from January to March
2017-2019, in the same period of 2020, the $\mathrm{NO}_{2}$ concentration decreased significantly, especially in February, when strict epidemic prevention and control actions were taken. In the case of relatively similar weather conditions, the decrease in $\mathrm{NO}_{2}$ concentrations in February 2020 fully demonstrated that the epidemic prevention and control action led to a significant improvement in air quality.

\section{$\underline{\mathrm{O}}_{3}$ Concentration}

The formation of urban $\mathrm{O}_{3}$ is a complicated process. $\mathrm{O}_{3}$ has no direct emission source. It is generated by the reaction of precursors such as $\mathrm{NO}_{\mathrm{x}}, \mathrm{CO}$, and VOCs (volatile organic compounds) under appropriate weather conditions (Saito et al., 2002; Schauer et al., 2007; Biswas et al., 2019). High concentrations of $\mathrm{O}_{3}$ can easily cause urban photochemical smog. The harm from $\mathrm{O}_{3}$ to the human body is mainly caused by the destruction of the respiratory tract mucosa, which results in various respiratory diseases and is also very irritating to the eyes (Monks et al., 2015; Turner et al., 2016).

It is worth noting that the pattern in the $\mathrm{O}_{3}$ concentrations was different from the pattern found for the other five air pollutants. As shown in Fig. 3(F)(a), in Anqing, Hefei, and Suzhou, in the month of January 2017-2019, the $\mathrm{O}_{3}$ concentrations ranged between 9.80 and 65.8, between 4.67 and 44.8 , and between 6.53 and $58.8 \mathrm{ppb}$, and averaged 31.2, 24.8 , and $27.1 \mathrm{ppb}$, respectively. Concentrations in January 2020 ranged from 8.87-56.9, 3.27-45.3, and $13.5-53.2 \mathrm{ppb}$ and averaged 30.4, 21.1, and $29.7 \mathrm{ppb}$, respectively. In Anqing and Hefei, the $\mathrm{O}_{3}$ concentration decreased slightly by $2.5 \%$ and $14.7 \%$, respectively, but in Suzhou, it increased by $9.5 \%$ compared with that in January 2017-2019. Based on the data from the three cities, in January 2020, the average $\mathrm{O}_{3}$ decreased by $2.6 \%$ compared with that in January 2017-2019.

As shown in Fig. 3(F)(b), in Anqing, Hefei, and Suzhou, in the month of February 2017-2019, the $\mathrm{O}_{3}$ concentrations ranged between 15.4 and 66.7, between 14.5 and 60.7 , and between 13.5 and $72.3 \mathrm{ppb}$ and averaged 37.933 .7 , and 37.3 $\mathrm{ppb}$, respectively. Concentrations in February 2020 ranged from $16.8-59.3,14.9-48.5$, and $11.2-54.6 \mathrm{ppb}$ and averaged 41.0, 34.8, and $37.1 \mathrm{ppb}$, respectively. In Anqing and Hefei, the $\mathrm{O}_{3}$ concentration increased slightly by $8.2 \%$ and $3.3 \%$, respectively, but in Suzhou, it decreased by $0.06 \%$ compared with that in January 2017-2019. Based on the data from the three cities, om February 2020, the average $\mathrm{O}_{3}$ increased by $3.6 \%$ compared with that in February 2017-2019. 


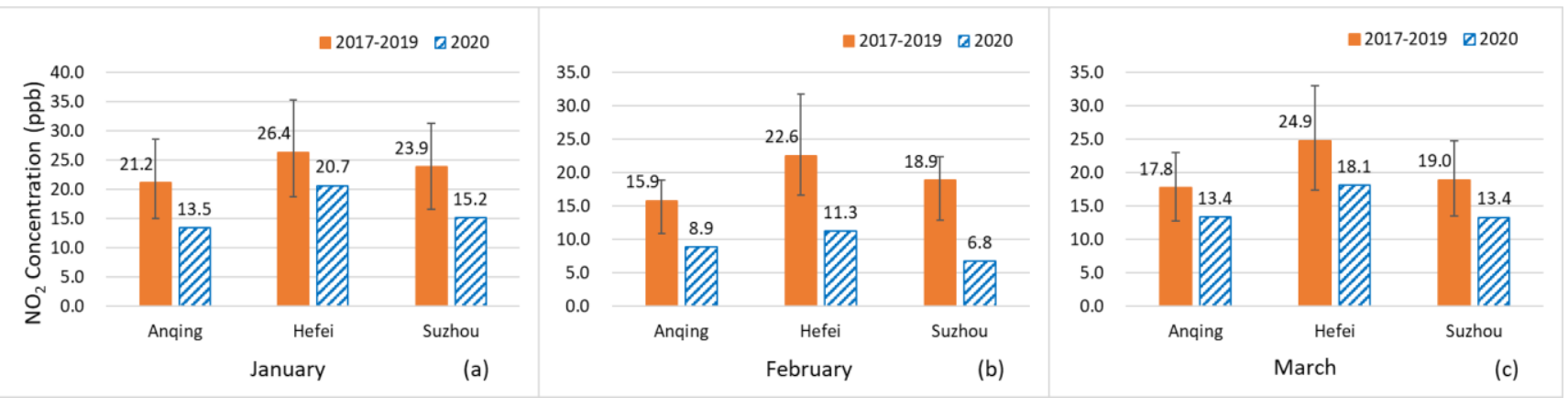

Fig. 3(E). The average concentrations of $\mathrm{NO}_{2}$ in January, February and March 2017-2019 and those in 2020, respectively.
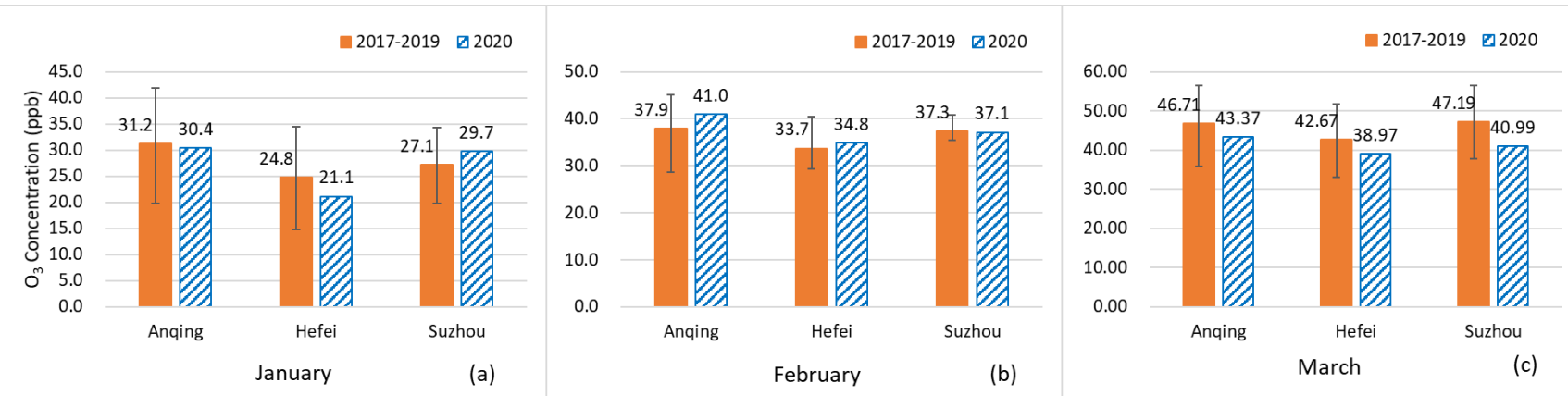

Fig. 3(F). The average concentrations of $\mathrm{O}_{3}$ in January, February and March 2017-2019 and those in 2020, respectively.

As shown in Fig. 3(F)(c), in Anqing, Hefei, and Suzhou, in the month of March 2017-2019, the $\mathrm{O}_{3}$ concentrations ranged between 19.1 and 72.3 , between 16.3 and 68.1 , and between 20.5 and $82.1 \mathrm{ppb}$ and averaged $46.7,42.7$, and $47.2 \mathrm{ppb}$, respectively. Concentrations in March 2020 ranged from 19.6-67.2, 11.2-59.3, and 15.4-66.3 ppb and averaged $43.4,39.0$, and $41.0 \mathrm{ppb}$, respectively, which reflected a decrease of $7.1 \%, 8.7 \%$, and $13.1 \%$ compared with that in March 2017-2019. Based on the data from the three cities, in March 2020, the average $\mathrm{O}_{3}$ decreased by $9.6 \%$ compared with that in March 2017-2019.

It can be seen that the fluctuation of $\mathrm{O}_{3}$ concentration was small compared with the obvious downward trend of the other five pollutants, and even showed a small increase (3.6\%) in February 2020. This was probably due to a lower concentration of $\mathrm{NO}_{2}$. The role of $\mathrm{NOx}$ in atmospheric photochemical processes can be summarized as a basic photochemical cycle:

$\mathrm{NO}_{2}+\mathrm{hv}(\lambda \leq 430 \mathrm{~nm}) \rightarrow \mathrm{NO}+\mathrm{M}$

$\mathrm{M}+\mathrm{O}_{2} \rightarrow \mathrm{O}_{3}$

$\mathrm{NO}+\mathrm{O}_{3} \rightarrow \mathrm{NO}_{2}+\mathrm{O}_{2}$

It can be seen that $\mathrm{NO}_{\mathrm{x}}$ is one of the important precursors to NO. A lower $\mathrm{NO}_{2}$ concentration will result in a lower level of $\mathrm{NO}$, thus reducing the possibility of $\mathrm{NO}$ reacting with $\mathrm{O}_{3}$ and thus preventing accumulation of $\mathrm{O}_{3}$. In general, the change in urban $\mathrm{NO}_{\mathrm{x}}$ and $\mathrm{O}_{3}$ concentrations exhibits a negative correlation, where this phenomenon is particularly obvious in winter. This is because in summer, due to strong solar radiation, photochemical reactions are more dominant, which makes the environment more suitable for the accumulation of $\mathrm{O}_{3}$. In winter, the photochemical reaction is relatively weak during the day, so higher $\mathrm{NO}_{2}$ concentrations in a specific range are conducive to the consumption of $\mathrm{O}_{3}$. However, a lower concentration of $\mathrm{NO}_{2}$ makes it impossible for the $\mathrm{O}_{3}$ generated during the day to be further effectively converted (Zhao et al., 2018), which explains why the $\mathrm{O}_{3}$ concentrations in Anqing, Hefei, and Suzhou were not significantly reduced from January to March of 2020.

\section{Distribution of the Six AQI Classes}

A statistical analysis was conducted in this study to determine the distribution of the six AQI classes in January, February and March 2017-2019 and those in 2020, respectively.

As Fig. 4(A)(a) shows, in Anqing, in January 2017-2019, the proportions of classes I, II, III, IV, V and VI were $6.5 \%$, $38.7 \%, 26.9 \%, 11.8 \%, 16.1 \%$ and $0 \%$, respectively. In January 2020, the proportions of AQI classes I, II, III, IV, V, and VI were $22.6 \%, 48.4 \%, 29.0 \%, 0 \%, 0 \%$, and $0 \%$, respectively. It can be seen that during January 2020, the combined proportions of Class I and Class II increased from $45.2 \%$ to $71.0 \%$, while the combined proportions of classes IV, V, and VI decreased from $28.0 \%$ to zero.

In Hefei (Fig. 4(A)(a)), in the month of January 20172019, the proportions of AQI classes I, II, III, IV, V and VI were $9.7 \%, 31.2 \%, 35.5 \%, 16.1 \%, 7.5 \%$ and $0 \%$, respectively. However, in January of 2020, the same AQI classes were $12.9 \%, 48.4 \%, 29.0 \%, 9.7 \%, 0 \%$, and $0 \%$, respectively. The combined proportions of Class I and II increased from $40.9 \%$ to $61.3 \%$, and the combined proportion of classes IV, 
$\mathrm{V}$, and VI decreased from $23.7 \%$ to $9.7 \%$. It can be seen that the air quality in Anqing and Hefei in January 2020 improved compared with the same period in the previous three years.

For Suzhou (Fig. 4(A)(a)), which had no significant change in air quality, in January 2017-2019, the proportions of classes I, II, III, IV, V, and VI were $1.1 \%, 32.3 \%, 28.0 \%$, $18.3 \%, 20.4 \%$, and $0 \%$, respectively. In January 2020, the AQI class proportions were $0 \%, 32.3 \%, 29.0 \%, 29.0 \%, 9.7 \%$, and $0 \%$. The combined proportion of Class I and Class II slightly decreased by $1.1 \%$, and the combined proportions $(38.7 \%)$ of classes VI, V, and VI were the same as those in January 2017-2019.

Fig. 4(A)(b) shows the distribution of the AQI classes for the three cities combination in January 2017-2019 and in January 2020, respectively. It can be seen that from 2017 to 2019, the distribution of AQI classes I, II, III, IV, V and VI in the three cities was $5.7 \%, 34.1 \%, 30.1 \%, 15.4 \%, 14.7 \%$ and $0 \%$, respectively, but in January 2020 , it was $11.8 \%$, $43.0 \%, 29.0 \%, 12.9 \%, 3.2 \%$, and $0 \%$, respectively. The combined proportions of classes I and II increased from $39.8 \%$ to $54.8 \%$, while the proportions of classes VI, V and VI decreased from $30.1 \%$ to $16.1 \%$, respectively. According to the data for the three cities, it can be seen that the air quality in Anhui Province in January 2020 improved compared with the same period in the previous three years. This may be because late January 2020 was the lunar New Year holiday in China. During this period, the factories were temporarily closed, resulting in a significant reduction in production and emissions.

As shown in Fig. 4(B)(a), in Anqing, in February 20172019, the proportions of classes I, II, III, IV, V, and VI were $14.3 \%, 38.1 \%, 35.7 \%, 8.3 \%, 2.4 \%$, and $1.2 \%$, respectively. In February 2020, when comprehensive epidemic prevention and control actions were taken, the proportions of classes I, II, III, IV, V, and VI were 37.9\%, 58.6\%, 3.4\%, 0\%, 0\%, and $0 \%$, respectively. It can be seen that during the epidemic control period, the combined proportions of Class I and Class II increased from $52.4 \%$ to $96.6 \%$, while the combined proportions of classes IV, V, and VI decreased from $11.9 \%$ to zero, which indicates that the air quality had greatly improved.

In Hefei (Fig. 4(B)(a)), in February 2017-2019, the proportions of classes I, II, III, IV, V, and VI changed to $9.5 \%, 39.3 \%, 46.4 \%, 4.8 \%, 0 \%$, and $0 \%$, respectively. However, in February of 2020, these proportions were $58.6 \%, 31.0 \%, 10.3 \%, 0 \%, 0 \%$, and $0 \%$. The combined proportions of classes I and II increased from $48.8 \%$ to $89.7 \%$ and the combined proportions of classes IV, V, and VI decreased from $4.8 \%$ zero.

For Suzhou (Fig. 4(B)(a)), in February 2017-2019, the proportions of classes I, II, III, IV, V, and VI were $2.4 \%$, $39.3 \%, 32.1 \%, 25.0 \%, 1.2 \%$, and $0 \%$, respectively. In February 2020 , the proportions changed to $27.6 \%, 51.7 \%, 20.7 \%, 0 \%$, $0 \%$, and $0 \%$. Similar to Anqing and Hefei, in Suzhou, in February 2020, the combined proportions of classes I and II increased from $41.7 \%$ to $79.3 \%$, and the combined proportions of classes IV, V, and VI dropped from $26.2 \%$ to zero. It was obvious that air quality improved significantly during the epidemic control period.

Fig. 4(B)(b) shows the distribution of the AQIs for the three cities combination in February 2017-2019 and in February 2020, respectively. It can be seen that from 2017 to 2019 , the AQI distribution of classes I, II, III, IV, V, and VI in the three cities was $8.7 \%, 38.9 \%, 38.1 \%, 12.7 \%, 1.2 \%$, and $0.4 \%$, respectively, but in February 2020, the distribution was $41.4 \%, 47.1 \%, 11.5 \%, 0 \%, 0 \%$, and $0 \%$, respectively. The combined proportions of classes I and II increased from $47.6 \%$ to $88.5 \%$, while the combined proportions of classes IV, V, and VI decreased from $14.3 \%$ to $0 \%$. Based on the results from these three cities, it is clear that in February 2020, the air quality improved significantly in the three cities. This is because in February 2020, comprehensive, strict COVID-19 epidemic prevention and control actions were taken in Anhui Province, and measures such as closing factories and restricting traffic greatly reduced the emission of air pollutants.

As shown in Fig. 4(C)(a), in Anqing, in March 2017-2019, the AQI proportions of classes I, II, III, IV, V and VI were $11.8 \%, 76.3 \%, 11.8 \%, 0 \%, 0 \%$ and $0 \%$, respectively. During March 2020, when comprehensive epidemic prevention and control actions were still taken, the proportions of classes I, II, III, IV, V, and VI were $32.3 \%, 67.7 \%, 0 \%, 0 \%, 0 \%$, and $0 \%$, respectively. The combined proportions of Class I and Class II increased from $88.2 \%$ to $100 \%$, which indicated that the air quality greatly improved during the epidemic control period.

In Hefei (Fig. 4(C)(a)), in March 2017-2019, the AQI proportions of classes I, II, III, IV, V and VI were $7.6 \%$, $75.0 \%, 17.4 \%, 0 \%, 0 \%$ and $0 \%$, respectively. However, in March of 2020, they were $25.8 \%, 71.0 \%, 3.2 \%, 0 \%, 0 \%$, and $0 \%$. The combined proportions of Class I and II increased from $82.6 \%$ to $96.8 \%$, while the combined proportions of Class IV, V, and VI was zero.

For Suzhou (Fig. 4(C)(a)), in March 2017-2019, the AQI proportions of classes I, II, III, IV, V, and VI were $2.2 \%$, $63.4 \%, 26.9 \%, 6.5 \%, 1.1 \%$, and $0 \%$, respectively. In March 2020 , the proportions were $9.7 \%, 83.9 \%, 6.5 \%, 0 \%, 0 \%$, and $0 \%$. The combined proportions of classes I and II increased from $65.6 \%$ to $93.5 \%$, while the combined proportions of classes IV, V, and VI decreased from $7.6 \%$ to zero. This indicated that the air quality in the three cities improved significantly during the epidemic control period.

Fig. 4(C)(b) shows the distribution of the AQI classes for three cities combination in March 2017-2019 and in March 2020, respectively. It can be seen that from 2017 to 2019 , the AQI distribution of classes I, II, III, IV, V and VI in the three cities was $7.2 \%, 71.6 \%, 18.7 \%, 2.2 \%, 0.4 \%$ and $0 \%$, respectively, but in March 2020, the distribution was 22.6\%, $74.2 \%, 3.2 \%, 0 \%, 0 \%$, and $0 \%$, respectively. The combined proportions of classes I and II increased from $78.8 \%$ to $96.8 \%$, while the combined proportion of classes IV, V, and VI decreased from $2.6 \%$ to zero. In March 2020, there was a significant improvement in air quality compared to the same period in the previous three years, which was due to the implementation of epidemic prevention and control actions.

\section{Indicatory Air Pollutants}

In order to further compare the changes in air quality during the epidemic control period, the five days with the highest daily AQI in February 2017-2019 and those of 2020 


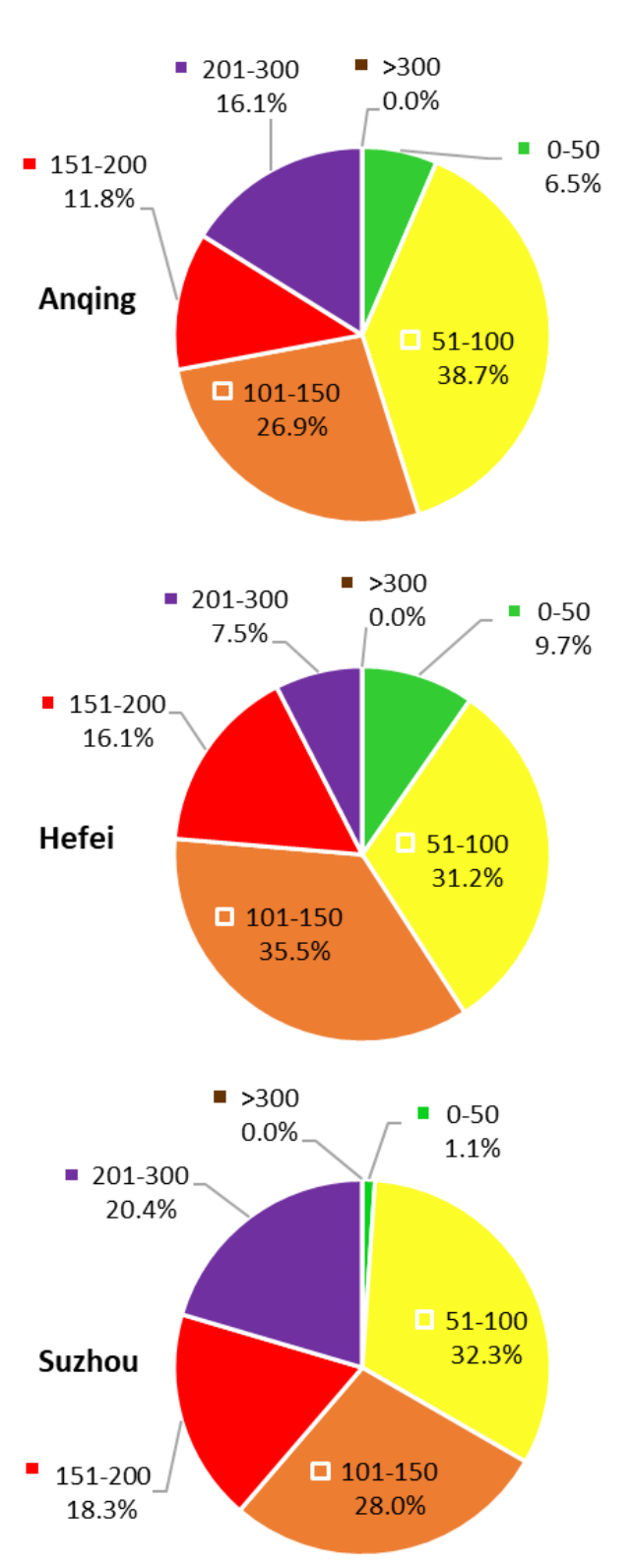

January 2017-2019
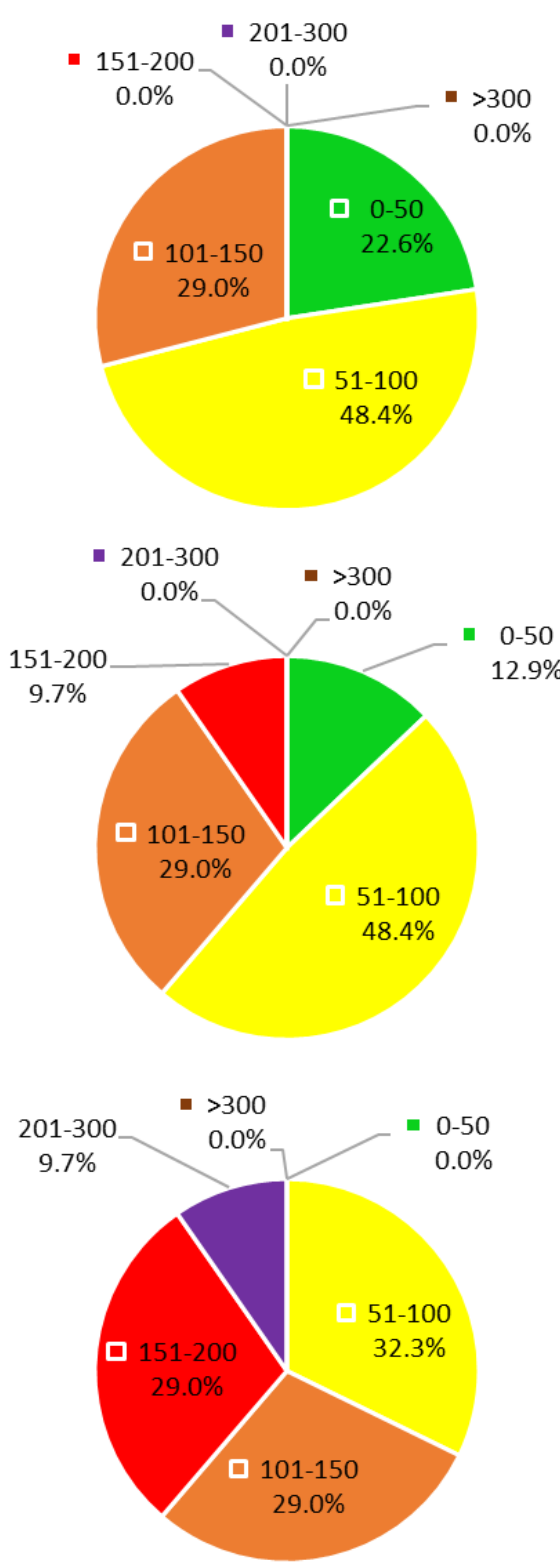

January 2020 (a)

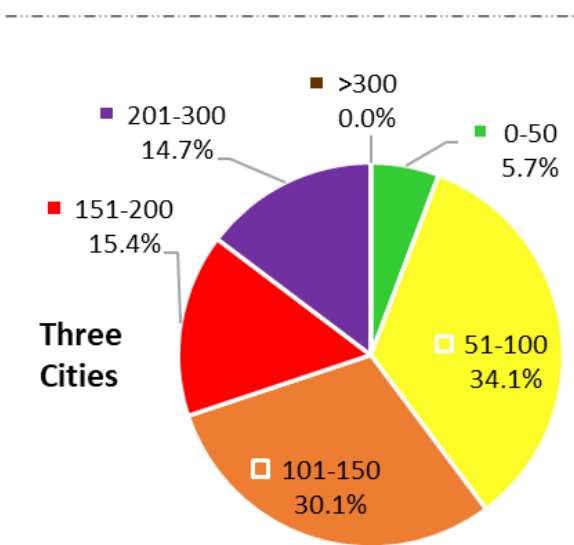

January 2017-2019

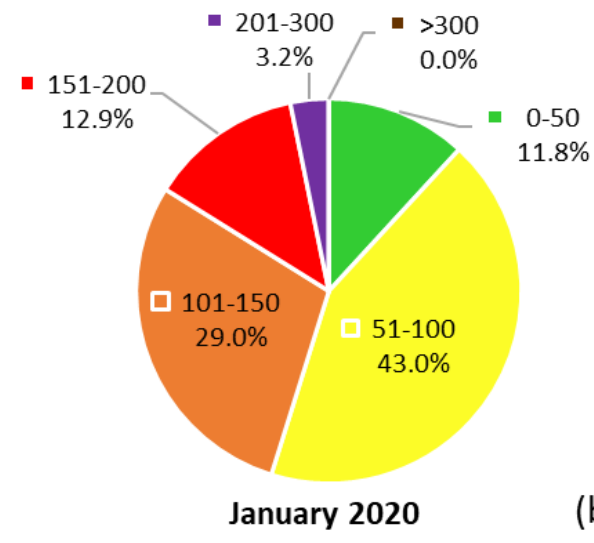

(b)

Fig. 4(A). The distribution of the six AQI classes (a) for Anqing, Hefei, and Suzhou in January 2017-2019 and January 2020, respectively and (b) for the three cities under observation. 


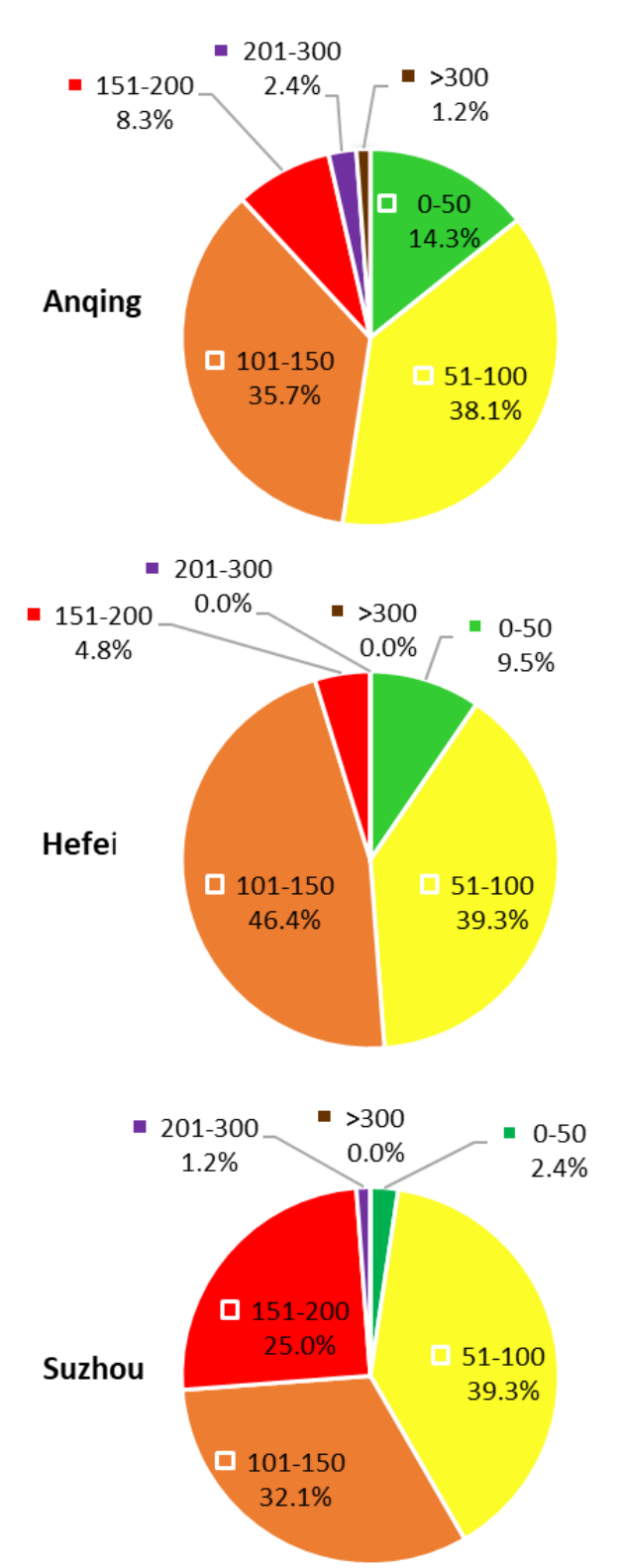

February 2017-2019
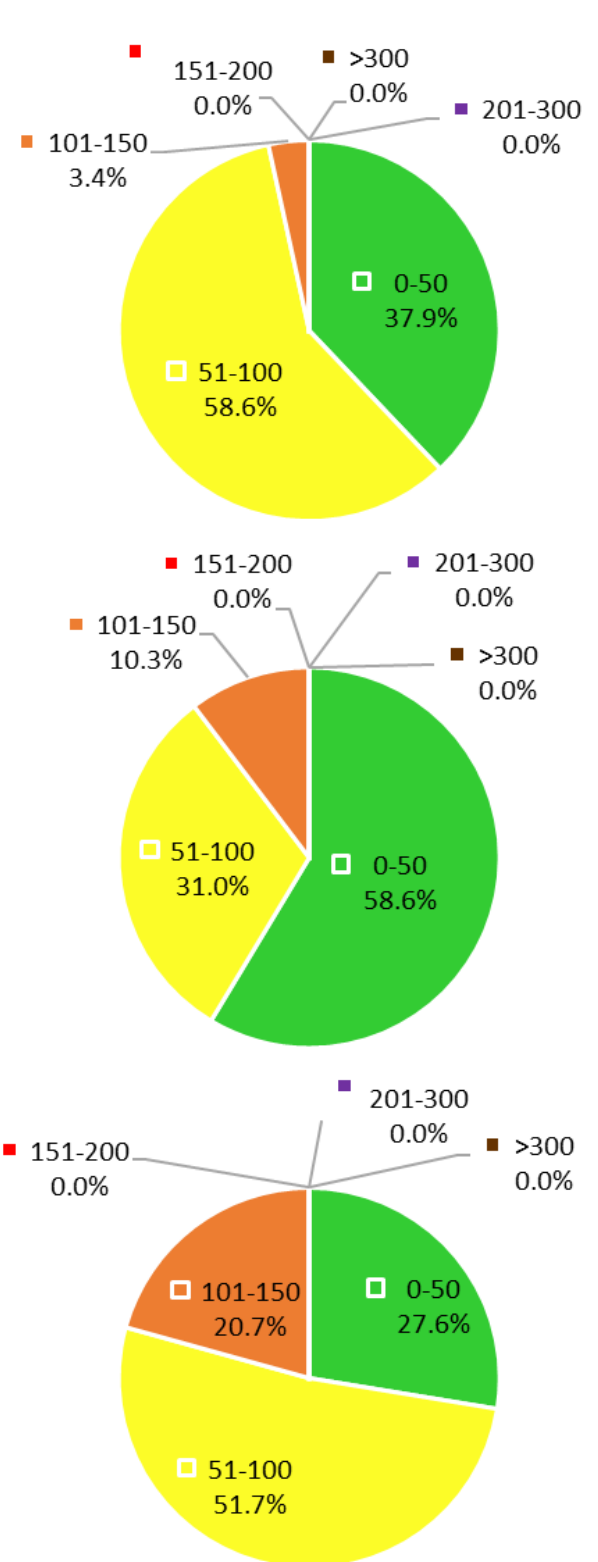

February 2020

(a)

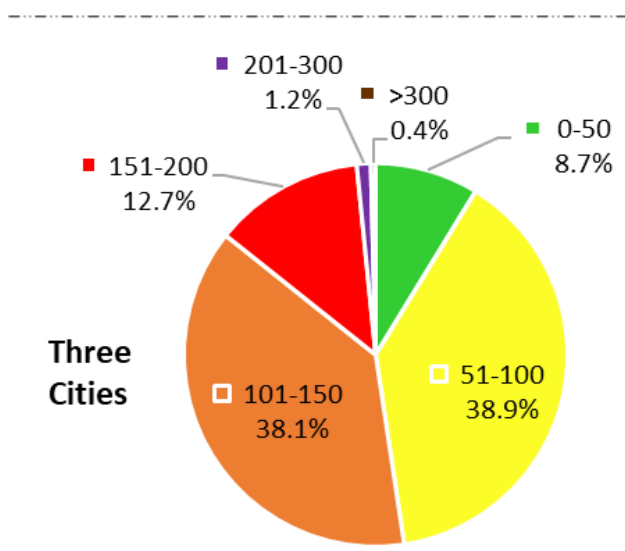

February 2017-2019

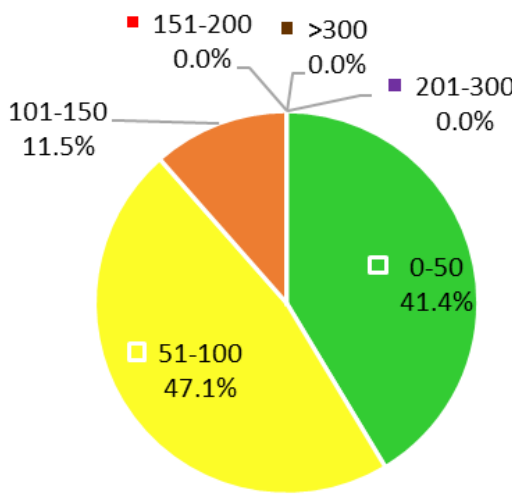

February 2020 (b)

Fig. 4(B). The distribution of the six AQI classes (a) for Anqing, Hefei, and Suzhou in February 2017-2019 and February 2020, respectively and (b) for the three cities under observation. 

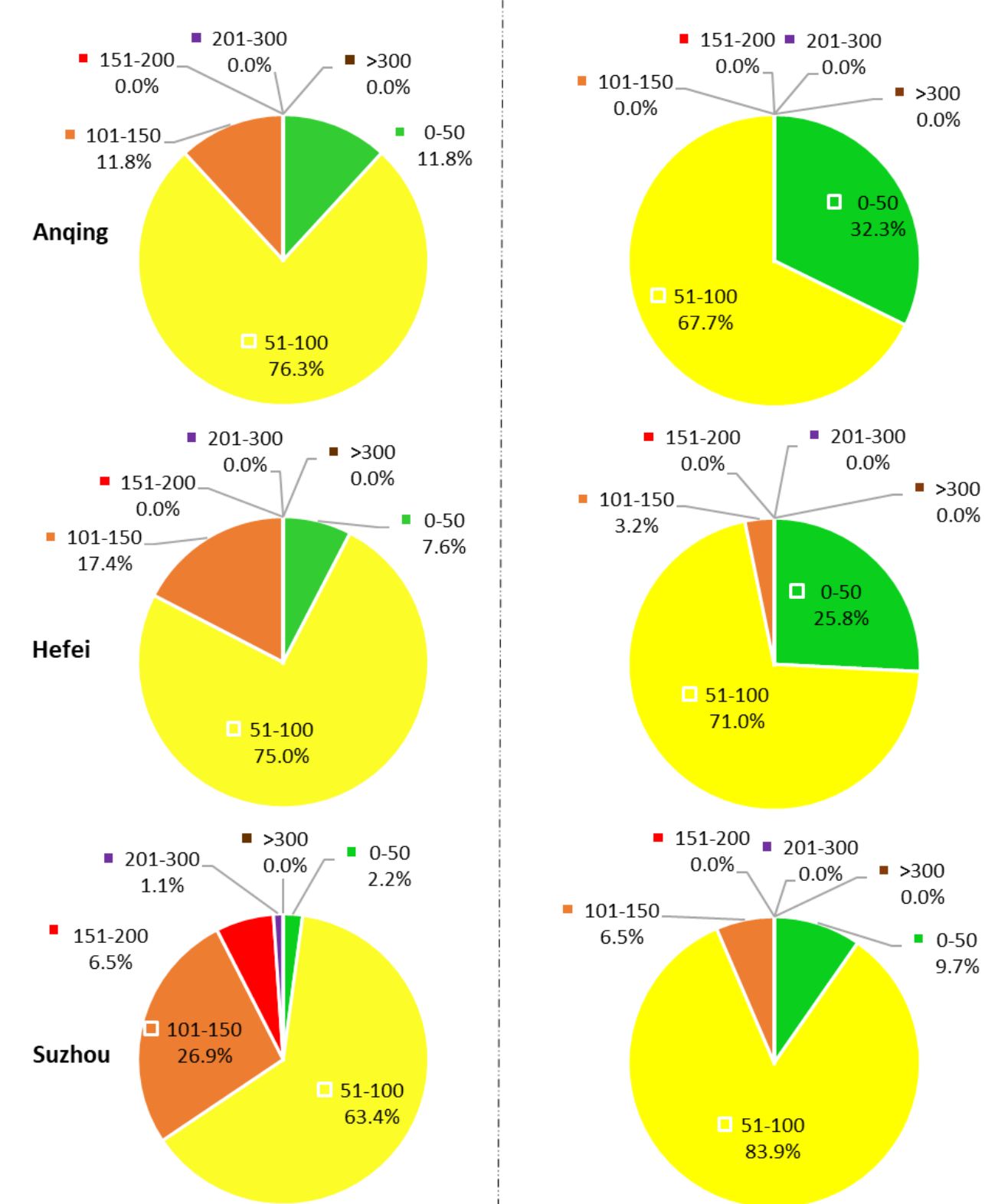

March 2017-2019

March 2020

(a)

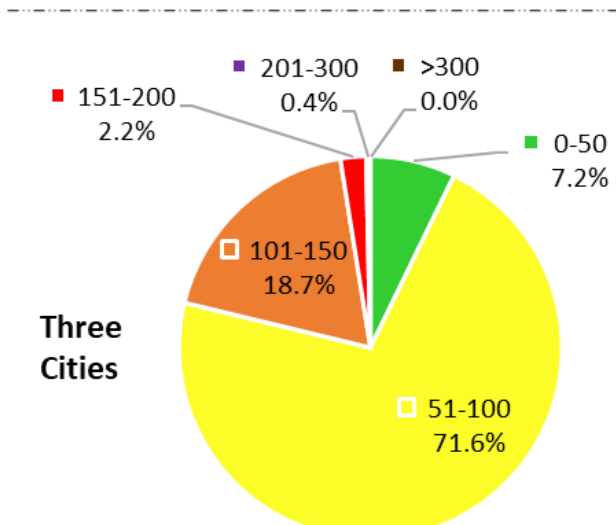

March 2017-2019

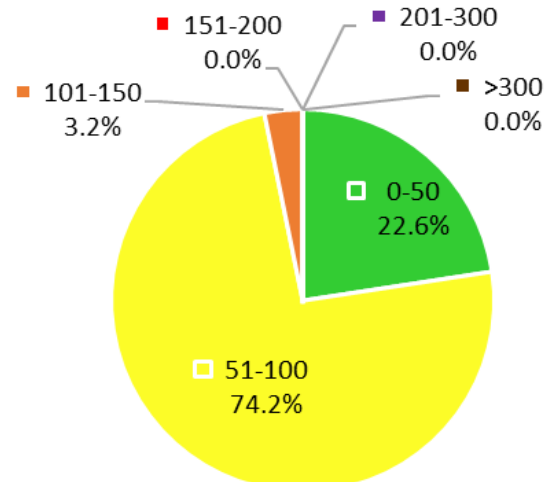

March 2020 (b)

Fig. 4(C). The distribution of the six AQI classes (a) for Anqing, Hefei, and Suzhou in March 2017-2019 and March 2020, respectively and (b) for the three cities under observation. 
for the three cities were analyzed and compared, as shown in Table 2.

It can be seen that in February 2017-2019, the AQI on the five days with the highest daily AQI ranged from193-303 and averaged 223.2, while those on the five days in February 2020 ranged from 114-132 and averaged 122.6, which was $45.1 \%$ lower than those in February 2017-2019. The indicatory air pollutant on the 10 days under observation was always $\mathrm{PM}_{2.5}$. The $\mathrm{PM}_{2.5}$ concentrations for the five days with the highest daily AQI in February 2017-2019 ranged from 145$253 \mu \mathrm{g} \mathrm{m}^{-3}$ and in an average of $173.6 \mu \mathrm{g} \mathrm{m} \mathrm{m}^{-3}$, while concentrations on the five days in February 2020 ranged from $86-100 \mu \mathrm{g} \mathrm{m}^{-3}$ and averaged $92.6 \mu \mathrm{g} \mathrm{m}^{-3}$, which was $46.7 \%$ lower than those in February 2017-2019. This shows that during the epidemic control period, the air quality near central China improved significantly.

\section{Comparison of Air Quality in Hubei and Anhui Provinces}

In a previous study, we investigated, compared, and analyzed the impact of the COVID-19 event on air quality in three cities, Wuhan, Jingmen, and Enshi, in Hubei Province, China (Xu et al., 2020).

In the combined data for the three cities in Hubei Province in the comparison and analysis of the six air pollutants in February 2020 when the comprehensive epidemic prevention and control actions were taken, the average concentrations of atmospheric $\mathrm{PM}_{2.5}, \mathrm{PM}_{10}, \mathrm{SO}_{2}, \mathrm{CO}$, and $\mathrm{NO}_{2}$ were $46.1 \mu \mathrm{g} \mathrm{m}^{-3}, 50.8 \mu \mathrm{g} \mathrm{m}^{-3}, 2.56 \mathrm{ppb}, 0.60 \mathrm{ppm}$, and $6.70 \mathrm{ppb}$ and were $30.1 \%, 40.5 \%, 33.4 \%, 27.9 \%$, and $61.4 \%$, respectively, lower than the levels in February 2017-2019. However, the $\mathrm{O}_{3}$ concentration in February 2020 increased by $14.3 \%$ compared with that in February 2017-2019. This was consistent with the conclusions drawn in this study, and more fully demonstrates that the COVID-19 epidemic prevention and control actions reduced the emissions of industrial and transportation exhaust and improved air quality. The increases in the $\mathrm{O}_{3}$ levels occurred because the lower concentration of $\mathrm{NO}_{2}$ resulted in constraints on the $\mathrm{NO}+\mathrm{O}_{3}$ reaction, and the $\mathrm{O}_{3}$ in the air could thus not be effectively further depleted.

For the combined distribution of AQIs in the three cities (Wuhan, Jingmen, and Enshi), in February 2020, when the strict epidemic prevention and control actions were taken, AQI classes I, II, III, IV, V and VI were $33.3 \%, 54.8 \%$, $9.5 \%, 2.4 \%, 0 \%$, and $0 \%$, respectively. The combined proportions of classes I and II increased from $63.3 \%$ to $88.1 \%$, while the combined proportion of classes IV, V, and VI decreased from $7.2 \%$ to $2.4 \%$, compared with that in the month of February 2017-2019 (non-epidemic period). The above results are also consistent with the those in this study. During the epidemic prevention and control period, the air quality greatly improved.

As for the indicatory air pollutants, the combined data for the three cities (Wuhan, Jingmen, and Enshi) in Hubei Province in February 2020, indicate that during the epidemic prevention and control period, the combined proportion of days during which $\mathrm{O}_{3}$ was as an indicatory pollutant in classes I and II increased significantly from $1.2 \%$ to $17.2 \%$, and the combined proportions of $\mathrm{PM}_{10}$ and $\mathrm{NO}_{2}$ as indicatory air pollutants decreased from $16.5 \%$ to $1.1 \%$, and from $7.3 \%$ to $0 \%$, respectively, compared with February 2017-2019. A similar conclusion was found in the present study, which indicated that during the epidemic control period, restrictions on transportation and production caused significant reductions in vehicle exhaust and industrial production emissions and improved the air quality.

\section{CONCLUSION}

In this study, the proportions of the six AQI classes for the three cities in the spring, summer, fall, and winter of 2017-2019 ranged between 22-500, 20-200, 20-431, and 222-303, and averaged 84.5, 78.1, 81.2, and 112.6, respectively. The AQI levels in the three cities in different seasons were in order as follows: winter $>$ spring $>$ fall $>$ summer, which indicated that the air quality in summer was much better than that in winter.

In terms of annual AQI characteristics, in Anqing, in 2017, 2018, and 2019, the daily AQI averaged 83.1, 77.3, and 83.2, respectively. In Hefei, it averaged 95.1, 79.5, and 87.6, respectively. In Suzhou, it averaged 109.4, 91.2, and 97.5 , respectively. Based on an analysis of the observation data for the three years under consideration, the AQI level rankings of the three cities were as follows: Suzhou $>$ Hefei $>$ Anqing. This showed that among the three cities from 2017-2019, Anqing had the best air quality, and Suzhou had the worst. Data from the three-year observation period show that the average annual AQI of the three cities was the lowest in 2018, but the air quality in 2019 deteriorated to a certain degree.

The indicatory air pollutants of AQI classes IV, V, and VI in the three cities from 2017-2019 were also analyzed. In the combined three-year data for the three cities, in classes IV, V, and VI, $\mathrm{PM}_{2.5}$ was the most important indicatory air pollutant, followed by $\mathrm{O}_{3}, \mathrm{PM}_{10}$, and $\mathrm{NO}_{2}$. The vast majority of AQI classes IV, V, and VI occurred in winter and spring, except the days when the indicatory air pollutant was $\mathrm{O}_{3}$, which occurred most in the summer. This is because the higher temperature and stronger solar radiation in summer are more conducive to the production and accumulation of $\mathrm{O}_{3}$.

The COVID-19 event has led to a significant improvement in air quality. In the month of January 2020, the average

Table 2. Indicatory air pollutants for the 5 days with the highest daily AQI for the three cities in February 2017-2019 and that in 2020, respectively.

\begin{tabular}{|c|c|c|c|c|c|}
\hline \multirow{2}{*}{ Year } & \multicolumn{2}{|c|}{$\mathrm{AQI}$} & \multicolumn{3}{|c|}{ Indicatory Air Pollutants } \\
\hline & Range & Mean & & Range & Mean \\
\hline 2017-2019 & $193-303$ & 223.2 & $\mathrm{PM}_{2.5}$ & $145-253$ & 173.6 \\
\hline 2020 & $114-132$ & 122.6 & $\mathrm{PM}_{2.5}$ & $86-100$ & 92.6 \\
\hline
\end{tabular}


concentrations of atmospheric $\mathrm{PM}_{2.5}, \mathrm{PM}_{10}, \mathrm{SO}_{2}, \mathrm{CO}$, and $\mathrm{NO}_{2}$ in the three cities (a combination of Anqing, Hefei, and Suzhou) were $23.8 \%, 33.9 \%, 54.4 \%, 16.7 \%$, and $31.5 \%$ lower than those in January 2017-2019, respectively. In February 2020, when the epidemic prevention and control actions were taken, the average concentrations of atmospheric $\mathrm{PM}_{2.5}, \mathrm{PM}_{10}, \mathrm{SO}_{2}, \mathrm{CO}$, and $\mathrm{NO}_{2}$ in three cities were $46.5 \%$, $48.9 \%, 52.5 \%, 36.2 \%$, and $52.8 \%$ lower than those in February 2017-2019, respectively, and in March 2020, they were $33.0 \%, 25.3 \%, 41.1 \%, 24.2 \%$, and $27.2 \%$ lower than those in March 2017-2019, respectively. Restrictions on industrial production and mobile transportation during the epidemic period (February and March 2020) were the main reasons for the significant reduction in air pollutant levels in ambient air.

The fluctuation in the $\mathrm{O}_{3}$ concentration was small compared with the obvious downward trend of the other five pollutants. In January, February, and March 2017-2019, the $\mathrm{O}_{3}$ concentrations averaged $27.7,36.3$, and $45.5 \mathrm{ppb}$, respectively, while in 2020 they were 27.1, 37.6, and 41.1 ppb, respectively. In January 2020 and March 2020, the $\mathrm{O}_{3}$ concentrations were $2.6 \%$ and $9.6 \%$, which was slightly lower than those in 2017-2019, respectively, and in February 2020 , there was even a small increase of $3.6 \%$. This is because a lower concentration of $\mathrm{NO}_{2}$ resulted in a hindering of the $\mathrm{NO}+\mathrm{O}_{3}$ reaction, so $\mathrm{O}_{3}$ was not depleted effectively.

Based on the distribution of the combined AQIs for the three cities, in January, February, and March 2020, the combined proportions of classes I and II increased by $15.1 \%, 40.9 \%$, and $18.0 \%$, respectively, while the combined proportions of classes IV, V and VI reduced by $14.0 \%$, $14.3 \%$, and $2.6 \%$, respectively. It is clear that during the epidemic prevention and control periods, the air quality near central China improved significantly.

In order to further compare the changes in air quality during the epidemic control period, in this study, the five days with the highest daily AQI in February 2017-2019 and those in 2020 for the three cities were also analyzed and compared. It can be seen that in February 2017-2019, the AQI on the five days averaged 223.2, while during the five days with the highest daily AQI in February 2020 averaged 122.6, which was $45.1 \%$ lower than that in February 20172019. The indicatory air pollutants on these 10 days was always $\mathrm{PM}_{2.5}$. The $\mathrm{PM}_{2.5}$ concentrations on the five days with the highest daily AQI in February 2020 averaged $92.6 \mu \mathrm{g} \mathrm{m}^{-3}$, which was $46.7 \%$ lower than those in February 2017-2019 $\left(173.6 \mu \mathrm{g} \mathrm{m}^{-3}\right)$. This shows that during the epidemic control period, the air quality near central China improved significantly.

This study provides useful information for the establishment of air pollution control strategies and for future research by scientific communities.

\section{REFERENCES}

Biswas, M.S., Ghude, S.D., Gurnale, D., Prabhakaran, T. and Mahajan, A.S. (2019). Simultaneous observations of nitrogen dioxide, formaldehyde and ozone in the IndoGangetic Plain. Aerosol Air Qual. Res. 19: 1749-1764. https://doi.org/10.4209/aaqr.2018.12.0484

Chatterton, T., Dorling, S., Lovett, A. and Stephenson, M. (2000). Air quality in Norwich, UK multi-scale modelling to assess the significance of city, county and regional pollution sources. Environ. Monit. Assess. 65: 425-433. https://doi.org/10.1007/978-94-010-0932-4_46

Cheng, N.L., Li, Y.T., Sun, F., Chen, C., Wang, B.Y., Li, Q., Wei, P. and Cheng, B.F. (2018). Ground-level $\mathrm{NO}_{2}$ in urban Beijing: Trends, distribution, and effects of emission reduction measures. Aerosol Air Qual. Res. 18: 343-356. https://doi.org/10.4209/aaqr.2017.02.0092

Fang, M., Chan, C.K. and Yao, X. (2009). Managing air quality in a rapidly developing nation: China. Atmos. Environ. 43: 79-86. https://doi.org/10.1016/j.atmosenv.2 008.09.064

Kim, E. and Hopke, P.K. (2008). Source characterization of ambient fine particles at multiple sites in the Seattle area. Atmos. Environ. 42: 6047-6056. https://doi.org/10.1016/ j.atmosenv.2008.03.032

Kulmala, M. (2015). China's choking cocktail. Nature 526: 497-499. https://doi.org/10.1038/526497a

Lee, Y.Y., Wang, L.C., Zhu, J.N., Wu, J.L. and Lee, K.L. (2018). Atmospheric $\mathrm{PM}_{2.5}$ and polychlorinated dibenzop-dioxins and dibenzofurans in Taiwan. Aerosol Air Qual. Res. 18: 762-779. https://doi.org/10.4209/aaqr.2018.02. 0050

Liang, D., Wang, Y.Q., Ma, C. and Wang, Y.J. (2016). Variability in transport pathways and source areas of $\mathrm{PM}_{10}$ in Beijing during 2009-2012. Aerosol Air Qual. Res. 16: 3130-3141. https://doi.org/10.4209/aaqr.2016.02. 0090

Liu, B., Sun, X., Zhang, J., Bi, X., Li, Y., Li, L., Dong, H., Xiao, Z., Zhang, Y. and Feng, Y. (2020). Characterization and spatial source apportionments of ambient $\mathrm{PM}_{10}$ and $\mathrm{PM}_{2.5}$ during the heating period in Tianjin, China. Aerosol Air Qual. Res. 20: 1-13. https://doi.org/10.4209/aaqr.201 9.06.0281

Matawle, J.L., Pervez, S., Dewangan, S., Shrivastava, A., Tiwari, S., Pant, P., Deb, M.K. and Pervez, Y. (2015). Characterization of $\mathrm{PM}_{2.5}$ source profiles for traffic and dust sources in Raipur, India. Aerosol Air Qual. Res. 15: 2537-2548. https://doi.org/10.4209/aaqr.2015.04.0222

Matus, K., Nam, K.M., Selin, N.E., Lamsal, L.N., Reilly, J.M. and Paltsev, S. (2012). Health damages from air pollution in China. Global Environ. Change 22: 0-66. https://doi.org/10.1016/j.gloenvcha.2011.08.006

Monks, P.S., Archibald, A.T., Colette, A., Cooper, O., Coyle, M., Derwent, R., Fowler, D., Granier, C., Law, K.S., Mills, G.E., Stevenson, D.S., Tarasova, O., Thouret, V., von Schneidemesser, E., Sommariva, R., Wild, O. and Williams, M.L. (2015). Tropospheric ozone and its precursors from the urban to the global scale from air quality to short-lived climate forcer. Atmos. Chem. Phys. 15: 8889-8973. https://doi.org/10.5194/acp-15-8889-2015

Saito, S., Nagao, I. and Tanaka, H. (2002). Relationship of $\mathrm{NO}_{x}$ and NMHC to photochemical $\mathrm{O}_{3}$ production in a coastal and metropolitan areas of Japan. Atmos. Environ. 36: 1277-1286. https://doi.org/10.1016/S1352-2310(01) 00557-X 
Schauer, J.J., Rogge, W.F., Hildemann, L.M., Mazurek, M.A., Cass, G.R. and Simoneit, B.R.T. (2007). Source apportionment of airborne particulate matter using organic compounds as tracers. Atmos. Environ. 30: 38373855. https://doi.org/10.1016/1352-2310(96)00085-4

She, Q., Peng, X., Xu, Q., Long, L., Wei, N. and Liu, M., Jia, W., Zhou, T., Han, J. and Xiang, W. (2017). Air quality and its response to satellite-derived urban form in the Yangtze river Delta, China. Ecol. Indic. 75: 297-306. https://doi.org/10.1016/j.ecolind.2016.12.045

Shen, F.Z., Ge, X.L., Hu, J.L., Nie, D.Y., Tian, L. and Chen, M.D. (2017). Air pollution characteristics and health risks in Henan Province, China. Environ. Res. Sci. 156: 625634. https://doi.org/10.1016/j.envres.2017.04.026

Song, Y., Tang, X., Xie, S., Zhang, Y., Wei, Y. and Zhang, M., Zeng, L. and Lu, S. (2007). Source apportionment of $\mathrm{PM}_{2.5}$ in Beijing in 2004. J. Hazard. Mater. 146: 124-130. https://doi.org/10.1016/j.jhazmat.2006.11.058

Tao, J., Ho, K.F., Chen, L., Zhu, L., Han, J. and Xu, Z. (2009). Effect of chemical composition of $\mathrm{PM}_{2.5}$ on visibility in Guangzhou, China, 2007 Spring. Particuology 7: 6875. https://doi.org/10.1016/j.partic.2008.11.002

Turner, M.C., Jerrett, M., Pope, C.A., Krewski, D. and Gapstur, S.M. (2016). Long-term ozone exposure and mortality in a large prospective study. Am. J. Respir. Crit. Care. Med. 193: 1134-1142. https://doi.org/10.1164/rcc m.201508-1633OC

Wang, H., Xu, J., Zhang, M., Yang, Y., Shen, X., Wang, Y., Chen, D. and Guo, J. (2014). A study of the meteorological causes of a prolonged and severe haze episode in January 2013 over central-eastern china. Atmos. Environ. 98: 146157. https://doi.org/10.1016/j.atmosenv.2014.08.053

Wang, W., Cui, K., Zhao, R., Hsieh, L.T. and Lee, W.J. (2018). Characterization of the Air Quality Index for Wuhu and Bengbu Cities, China. Aerosol Air Qual. Res. 18: 1198-1220. https://doi.org/10.4209/aaqr.2018.04.0135

World Health Organization (WHO) (2014). World health statistics 2014. https://www.who.int/gho/publications/wo rld_health_statistics/2014/en/

Wu, S.P., Xu, C., Dai, L.H., Zhang, N., Wei, Y., Gao, Y., Yan, J.P. and Schwab, J.J. (2019a). Source apportionment of $\mathrm{PM}_{2.5}$ at urban and suburban sites in a port city of southeastern China. Aerosol Air Qual. Res. 19: 20172031. https://doi.org/10.4209/aaqr.2019.01.0007

Wu, Y., Lu, B., Zhu, X., Wang, A., Yang, M., Gu, S., Wang, X., Leng, P., Zierold, K.M., Li, X., Tang, K.K., Fang, L., Huang, R., Xu, G. and Chen, L. (2019b). Seasonal variations, source apportionment, and health risk assessment of heavy metals in $\mathrm{PM}_{2.5}$ in Ningbo, China. Aerosol Air Qual. Res. 19: 2083-2092. https://doi.org/10.4209/aaqr.2 018.12 .0452

Xu, G., Jiao, L.M., Zhang, B.E., Zhao, S.L., Yuan, M., Gu, Y.Y., Liu, J.F. and Tang, X. (2017). Spatial and temporal variability of the $\mathrm{PM}_{2.5} / \mathrm{PM}_{10}$ ratio in Wuhan, central China. Aerosol Air Qual. Res. 17: 741-751. https://doi.org/10.42 09/aaqr.2016.09.0406

Xu, K.J., Cui, K.P., Young, L.H., Hsieh, Y.K., Wang, Y.F., Wan, S. and Zhang, J.J. (2020). Impact of the COVID-19 event on air quality in central China. Aerosol Air Qual. Res. 20: 915-929. https://doi.org/10.4209/aaqr.2020.04.0150

Zhao, R., Cui, K.P., Wang, W.W., Wang, L.C. and Yan, P. (2018). Atmospheric $\mathrm{PM}_{2.5}$ and total PCDD/Fs-WHO $\mathrm{W}_{2005}$ TEQ level: A case of Handan and Kaifeng cities, China. Aerosol Air Qual. Res. 18: 994-1007. https://doi.org/10.4 209/aaqr.2018.02.0040

Zhou, Y., Wu, Y., Yang, L., Fu, L.X., He, K.B., Wang, S.X., Hao, J.M., Chen, J.C. and Li, C.Y. (2009). The impact of transportation control measures on emission reductions during the 2008 Olympic Games in Beijing, China. Atmos. Environ. 44: 285-293. https://doi.org/10.1016/j.at mosenv.2009.10.040

Received for review, April 4, 2020 Revised, April 22, 2020 Accepted, May 22, 2020 